\title{
General Features of Extreme Rainfall Events Produced by MCSs over East China during 2016-17
}

\author{
LiU ZHANG, JiNZHONG Min, AND XiAORAN ZHUANG
}

\author{
Collaborative Innovation Center on Forecast and Evaluation of Meteorological Disasters, Key Laboratory of Meteorological \\ Disaster of Ministry of Education, Nanjing University of Information Science and Technology, and Jiangsu Research Institute \\ of Meteorological Science, Nanjing, China \\ RUSS S. SCHUMACHER \\ Department of Atmospheric Science, Colorado State University, Fort Collins, Colorado
}

(Manuscript received 21 December 2018, in final form 9 April 2019)

\begin{abstract}
This study investigated the characteristics of extreme precipitation events associated with mesoscale convective systems (MCSs) in East China (the area east of $96^{\circ} \mathrm{E}$ ) during 2016-17. Over the entire region, 204 events were first identified and classified into synoptic, tropical, MCS, small-scale-storm (SSS), and unclassified types. For 73 MCS-type events, further division and analysis were conducted according to the organizational modes. Results show that MCS-related events occurred most frequently near southern Fujian Province and from April to October with a peak in July. The area of occurrence shifted from the south in spring to the north in summer before going back to the south in autumn. The events occurred most commonly from afternoon to early evening, matured around late afternoon, and ended before dark. Among MCS subcategories, the longest average duration was seen in the multiple-MCS cases. Of the 15 selected multipleMCS events, 11 were defined as early-maturing type with peak rainfall occurrence before the midpoint of duration while the others were late maturing. Although multiple-MCS events were accompanied by a southwest low-level jet, strong warm-air advection, and convective instability, early-maturing cases had stronger synoptic-scale ascent, moister environments, and smaller surface-based convective available potential energy (SBCAPE) and convection inhibition (SBCIN) at the most extreme rainfall-occurrence point. Compared to the MCS type within all extreme precipitation events over the United States, the percentage was lower in China. However, the events in China exhibit more pronounced seasonal cycle.
\end{abstract}

\section{Introduction}

East China, defined here as the area east of $96^{\circ} \mathrm{E}$, is adjacent to the western Pacific Ocean and located in the East Asian monsoon region. Influenced by factors such as geographical location, topography, and monsoon, it is one of the areas in the world most frequently affected by hazardous heavy rainfall (e.g., Ye and Huang 1996; Huang et al. 1998; Tao et al. 1998; Huang et al. 2005). Heavy rainfall over East China, especially in summer, is usually sudden, frequent, and persistent, often leading to significant impact on life and property.

As documented in the literature, extreme precipitation induced by deep, moist convection is often associated with mesoscale convective systems (MCSs). Moore et al. (2003)

\footnotetext{
Corresponding author: Jinzhong Min, minjz@nuist.edu.cn
}

investigated synoptic and mesoscale conditions for extreme rainfall events related to MCSs in the midwestern United States. Furthermore, Schumacher and Johnson (2006, hereafter SJ06) and Stevenson and Schumacher (2014) examined extreme precipitation events in the area east of Rocky Mountains and found that over $65 \%$ events resulted from MCSs, and only $25 \%$ were caused by synoptic weather systems.

Heavy-rainfall-producing MCSs can be organized in a variety of ways. Some evolve as isolated or discrete cells, whereas others occur within large complexes or lines. Many studies have shown that the organization of MCSs is a key factor to determine whether they can produce heavy rainfall (e.g., Houze et al. 1990; Loehrer and Johnson 1995; Schiesser et al. 1995; Parker and Johnson 2000, hereafter PJ00; Jirak et al. 2003, hereafter J03; Johnson 2004; Rigo and Llasat 2004; Rigo and Llasat 2007). 
For example, Houze et al. (1990) found that nonlinear MCSs are less likely to produce flash flooding than linear ones. Among linear MCSs that produce heavy rainfall, PJ00 discovered three dominant modes of organization over the United States: MCSs with trailing stratiform (TS), leading stratiform (LS), and parallel stratiform (PS) precipitation. While TS is the most common mode, LS and PS modes are not negligible and contribute to flash flooding in some cases, especially LS MCSs. Additionally, SJ06 described two most frequently observed MCS patterns leading to extreme rainfall, namely training line-adjoining stratiform (TL/AS) and back-building (BB). The differences in MCS organizations may affect the amount of stratiform precipitation generated by a system, and consequently the rainfall totals.

With different organizational structures, heavy-rainfallproducing MCSs may have different spatial-temporal characteristics (e.g., Davis 2001; Yu et al. 2007; Pope et al. 2008; Zheng et al. 2008; Zhou et al. 2008; Zheng et al. 2013; Chen et al. 2013; Meng et al. 2013; Yang et al. 2015). Zhou et al. (2008) revealed that the diurnal variation of precipitation in the middle and lower reaches of the Yangtze River has two peaks, which occur in the afternoon and early morning, respectively. Zheng et al. (2008) also obtained similar results from the statistics of MCSs in China. Yu et al. (2007) provided evidence that the afternoon peak in precipitation in this area is often caused by convective activities with a short life span (less than $3 \mathrm{~h}$ ), while the peak from night to early morning is related to the activities of MCSs with a long life (greater than $6 \mathrm{~h}$ ). On the other hand, for MCSs of a given organizational mode to occur, typical synoptic and mesoscale conditions must be in place. Climatological studies have shown that organization of MCSs is associated with CAPE, vertical wind shear, and moisture (e.g., Moncrieff and Green 1972; Houze 1977; Houze et al. 2007; Rotunno et al. 1988; Laing and Fritsch 2000; Pettet and Johnson 2003; Johnson et al. 2005). For instance, Laing and Fritsch (2000) showed that mesoscale convective complexes (MCCs) generally initiate within baroclinic zones characterized by locally large vertical wind shear and CAPE, while elongated meso- $\beta$-convective systems frequently occur in environments with lower CAPE (J03). PJ00 summarized the changes in the wind field and vertical shear for TS, LS, and PS in the United States. It was found that the average storm-relative winds both $5-8$ and $3-10 \mathrm{~km}$ above the ground were the most different among the three types, which indicates that the airflow relative to the convective line in the upper troposphere mainly determines the organization of MCSs. These ideas are of practical importance for the prediction of MCS-caused extreme precipitation. The evolution of the MCS, which depends on the general features and environmental conditions of its life cycle is the physical basis for the forecast (Vila et al. 2008).

During the warm season from May to September, MCSs are the main heavy rainfall producers in East China (e.g., Wang and Cui 2012). Although there have been studies on the organization of warm-season MCSs responsible for extreme rainfall over East China based on individual cases (e.g., Yue et al. 2008; Wang et al. 2011; Yi et al. 2011; Zheng et al. 2013; Luo et al. 2014; Chen et al. 2016), research based on large numbers of cases are still comparatively lacking. Additionally, despite the experiences in previous studies, the forecast accuracy of heavy rainfall in China is still relatively low, affirming that the characteristics of the initiation, organization, development and maintenance of MCSs in heavy rainfall are extremely complicated. Moreover, meteorologists' understanding of the occurrence and development of MCS-caused heavy rainfall is far from meeting the needs of the development of numerical models. Therefore, it is necessary to deepen the study of MCS-related extreme rainfall events.

The main purpose of this study is to characterize the spatial-temporal distribution and environmental properties of the MCS-caused extreme rainfall events over East China (Fig. 1). To this end, we examine the observations of 2 years (2016-17) from the composite Doppler radar mosaics and historical weather maps. Meanwhile, the initial environmental conditions of one certain pattern are analyzed further with a reanalysis dataset. Only 2 years were selected because of the unavailability of long-term radar mosaics. However, the study area has high frequency of extreme rainfall events in these 2 years.

This paper is organized as follows. Section 2 describes the selection of the extreme rainfall occurrences and determination of the extreme rainfall events. The detailed extreme rainfall types are described in section 3 . The overall analysis of spatial and temporal characteristics for MCS-related extreme rainfall events are presented in section 4 . In section 5 , the precipitation characteristics and environmental conditions for one pattern of MCS type are investigated, and two specific cases of this pattern are analyzed in section 6. Section 7 provides a comparison of extreme rainfall features between China and the United States. Finally, section 8 gives a summary of the results in this study.

\section{Selection of the extreme rainfall occurrences and determination of the extreme rainfall events}

The hourly precipitation dataset of China's national surface stations ( 2479 stations) provided by the National Meteorological Information Center (NMIC) of the 


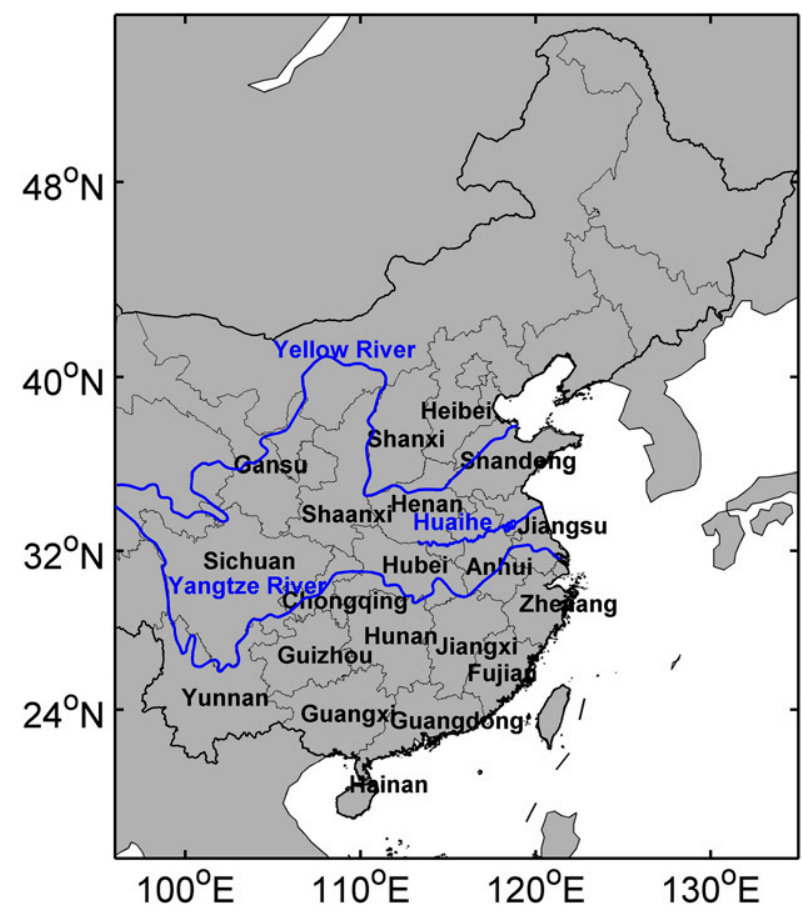

FIG. 1. A map of East China with the names of related provinces and the rivers (blue lines).

China Meteorological Administration (CMA) was used to select the extreme rainfall occurrences and discover each extreme rainfall event. This dataset was established by collecting and sorting all types of historical hourly precipitation data sources in China. The quality assessment results showed that the data availability of most stations exceeded $90 \%$, and the data accuracy rate of $99.3 \%$ stations was greater than $98 \%$ (Zhang et al. 2016).

In the conceptual framework used here, an extreme rainfall occurrence was defined as an hour in which the precipitation exceeded the threshold, while a rainfall event was defined as precipitation for hours. Then, a rainfall event having at least one hourly extreme occurrence was defined as an extreme rainfall event. In other words, an extreme rainfall event could include hourly extreme occurrences and precipitation leading up to and following an extreme occurrence. West China (west of $96^{\circ} \mathrm{E}$ ) with sparse stations, often considered an arid region in previous studies (e.g., Yan and Yang 2000; Zhai et al. 2005; Zhai and Zou 2005; Yu et al. 2011; Huang et al. 2015), was excluded from this study.

According to the definitions above, the first step of determining extreme rainfall events from 2016 to 2017 was to discern hourly extreme precipitation occurrences. As illustrated in previous studies, the percentile-based method was currently widely used to study extreme precipitation. Thus, the 99.99 th percentile was applied in

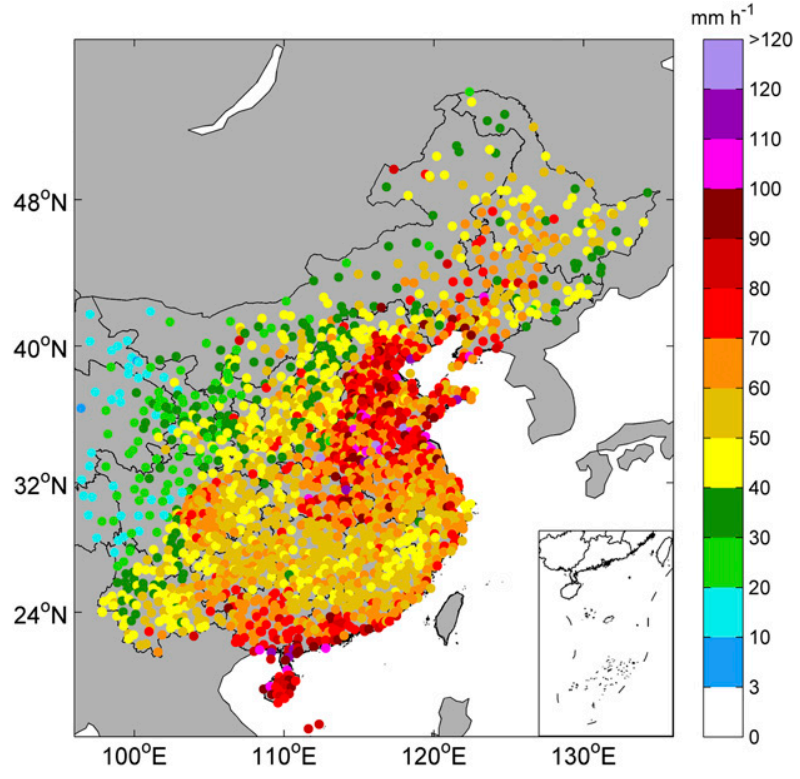

FIG. 2. Distribution of the hourly precipitation threshold for each gauge determined by 99.99 th percentile method.

the current study to select hourly extreme rainfall occurrences. As such, for each station, an hourly extreme rainfall occurrence during 2016-17 was defined as an hourly phenomenon with precipitation exceeding the 99.99th percentile of all precipitation hours during 19812017 (Fig. 2). The following step was to identify rainfall events from time series for stations with hourly extreme precipitation occurrences. In this study, the beginning of a rainfall event referred to the first time when hourly rainfall value was greater than $0.1 \mathrm{~mm} \mathrm{~h}^{-1}$. If there was no precipitation for three consecutive hours after a specific time, the time was then defined as the end of the event. Generally, the value of $0.1 \mathrm{~mm} \mathrm{~h}^{-1}$ was used to distinguish whether there was precipitation because very light precipitation (less than $0.1 \mathrm{~mm} \mathrm{~h}^{-1}$ ) is recorded as no precipitation in the dataset. Therefore, for each extreme-occurrence station, a precipitation event between 2016 and 2017 was defined as hourly precipitation of at least $0.1 \mathrm{~mm} \mathrm{~h}^{-1}$ for hours and until three consecutive hours of no precipitation was reported. The last step was to combine the results of the former two requirements and identify extreme rainfall events in such a way that if there was at least one hourly extreme occurrence during a precipitation event, the precipitation event was considered as an extreme rainfall event for that particular station.

\section{Extreme rainfall types}

The composite Doppler radar mosaics provided by NMIC and weather maps provided by Korea 


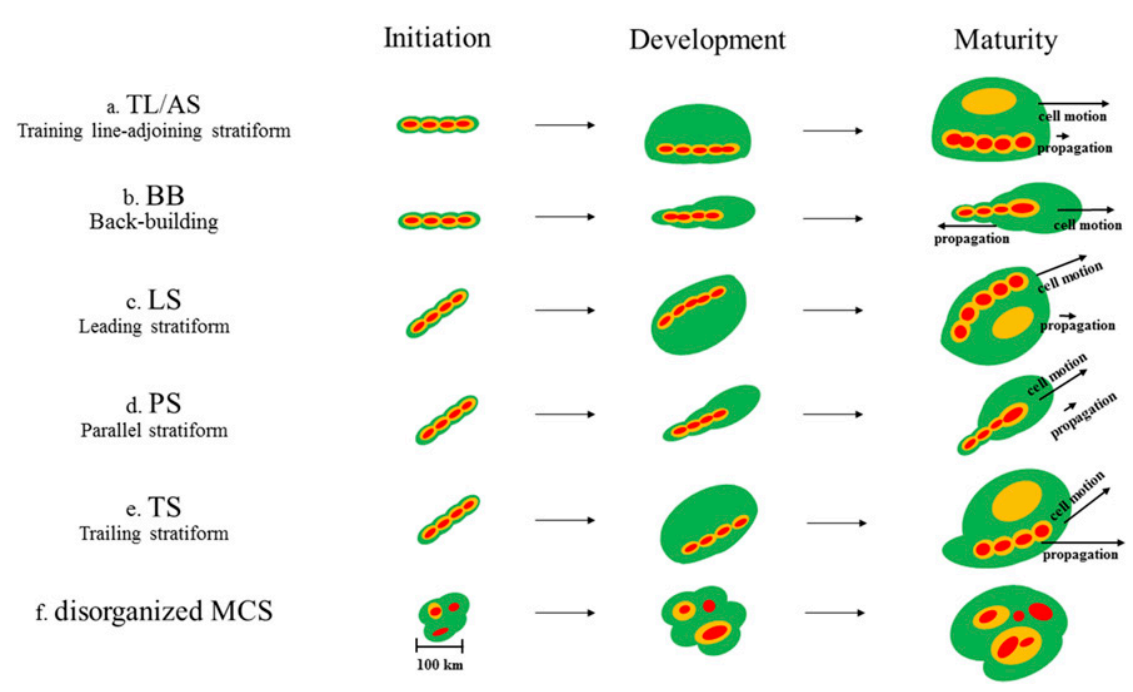

FIG. 3. Schematic diagram of the radar-observed features of each pattern of extreme-rainproducing MCSs. Shading represents approximate radar reflectivity values of 20, 40, and $>40 \mathrm{dBZ}$. Representative propagation and cell motion are also shown in all maturity panels.

Meteorological Administration (KMA) were visually examined to discover systems covering the duration of each extreme rainfall event. Occasionally, events of nearby stations may be from the same systems within a close time period. In such a case, the events were considered as the same in the final set. Moreover, a rainfall case was eliminated when there was no radar data and weather map available to match. After eliminating invalid results, 204 extreme precipitation events were kept as the sample size in this study and then divided into five types: synoptic, tropical, MCSs, small-scale-storm (hereafter SSS), and unclassified events.

\section{a. Synoptic and tropical}

The definition of synoptic cases in this study is the same as that defined by Luo et al. (2016, hereafter L16). Namely, events resulting from synoptic systems that lasted over $24 \mathrm{~h}$ were defined as synoptic type. However, it must be mentioned that an event was classified as multiple-MCS type when the convection organized into multiple MCSs even if the duration was more than $24 \mathrm{~h}$. Subsequently, events caused by fronts were subclassified into front type, while the cases with the same duration definition but caused by strong vortices or shear lines were regarded as vortex or shear line type. Additionally, tropical-system type refers to events that were initiated by tropical cyclones or their remnants.

\section{b. MCSs}

In this study, MCSs are convective systems that have at least one convection zone (with reflectivity greater than $40 \mathrm{dBZ}$ ) located in a stratiform region (with reflectivity greater than $20 \mathrm{dBZ}$ ), an extent of greater than $100 \mathrm{~km}$ in one direction, and duration from 3 to $24 \mathrm{~h}$. Events were classified as MCS type if they were results of MCSs. Similar to SJ06, MCS events were arranged into seven subtypes, namely TL/AS, BB, LS, PS, TS, disorganized, and multiple MCSs. Each subclassification of MCS events was named by organization and motion of the systems that produced the extreme rainfall.

According to the organizational modes, MCSs were first divided into disorganized (Fig. 3f) and linear archetypes (Figs. 3a-e), in which disorganized MCSs featured unorganized strong convective echoes embedded within large areas of stratiform echoes. Among the linear-mode MCSs, LS, PS, and TS MCSs (Figs. 3c-e) were convective lines with leading stratiform, parallel stratiform and trailing stratiform rainfall, respectively. The TS, LS, and PS morphologies were first proposed by PJ00 and were later extended to include the TL/AS and BB categories by SJ06. A linear MCS with cell motion approximately parallel to the convective line was termed as TL/AS (Fig. 3a), while BB was characterized by a line or cluster of quasi-stationary or back-building convection (Fig. 3b).

Additionally, an event affected by multiple different MCSs was defined as multiple-MCS type. It is worth noting that merging and splitting occurring within the life cycle of MCSs play an important role in determining whether one case belongs to multiple-MCS type or not. Thus, in this study, if systems merged, the merged system was treated as a continuation of the system that was closest to it at the previous hour before merging, and the other systems were regarded as dissipated. If one system 

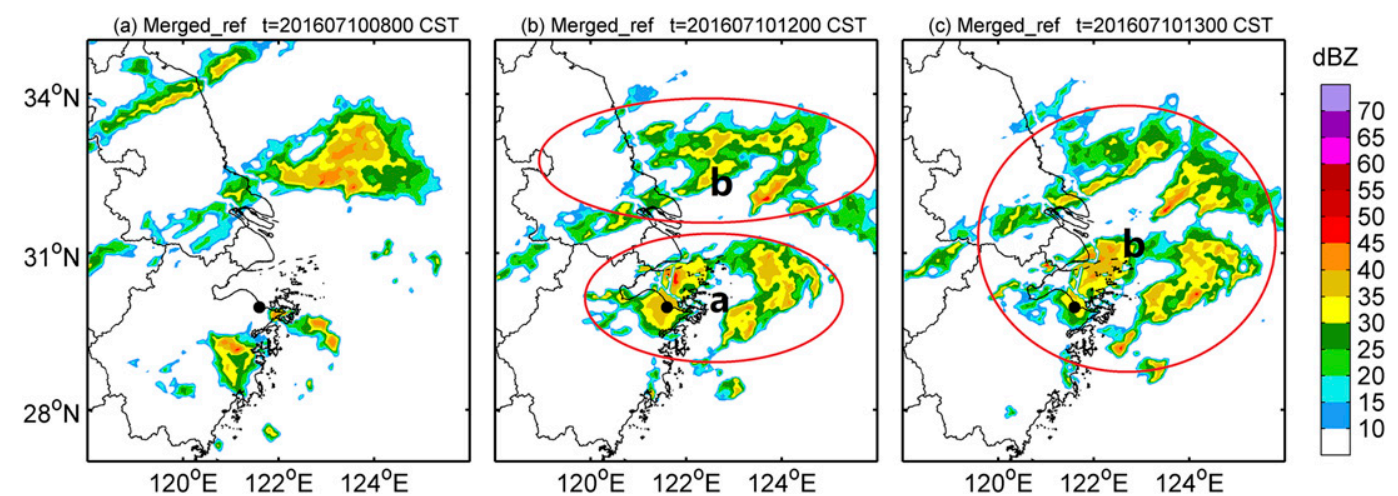

FIG. 4. Composite radar reflectivity (dBZ) from a merged MCSs event at (a) 0800, (b) 1200, and (c) 1300 CST 10 Jul 2016. Times are (local) CST (China standard time, CST $=$ UTC +0800 ). Map boundary is the same for all panels, and the black point is the position of the rainfall gauge that recorded the most extreme rainfall occurrence during the event.

split, the system closest to it at the next time was considered as a continuation of the original system, and other systems were seen as new systems. Accordingly, one extreme precipitation event would be classified into multiple-MCS type if it was affected by both the original system and new systems generated by splitting or merging.

Radar data from a merged MCSs event are shown in Fig. 4. A small area of convection, oriented nearly eastward, developed north of Zhejiang Province around 0800 CST (China standard time, CST $=$ UTC $+8 \mathrm{~h}$ ) 10 July 2016 (Fig. 4a) and intensified through 1200 CST (MCS a in Fig. 4b). By 1300 CST, this MCS moved northward and merged with MCS $b$ west of Jiangsu Province. With the centroid closer to the system north of the original convection, the merged MCS was considered as a different system (Fig. 4c), and the case was arranged into a multiple-MCS event.

In the split MCS case on 19 August 2017, MCS a moved from North China to the junction of Jiangsu and Anhui at about 1842 CST (Fig. 5a). During the stay along coastal area in East China, the convection split into two systems till 2136 CST (Fig. 5b), in which the front-flank cell gradually weakened and split again. However, the rear-flank MCS b, regarded as another MCS different with the previous system, remained in place (Fig. 5c) and merged with the convection to both its east and west sides subsequently, keeping affecting the rainfall area.

\section{c. SSS}

It was also found that there were several cases caused by single convective cells whose reflectivity or duration did not meet the threshold of an MCS. Such events were classified as small-scale storm type. As documented in L16, compared with MCSs, single convective cells may exert less extensive influence on the rainfall due to the smaller size and shorter duration.

\section{d. Unclassified}

In addition to the above, cases occurring without significant influence of synoptic systems, tropical systems,
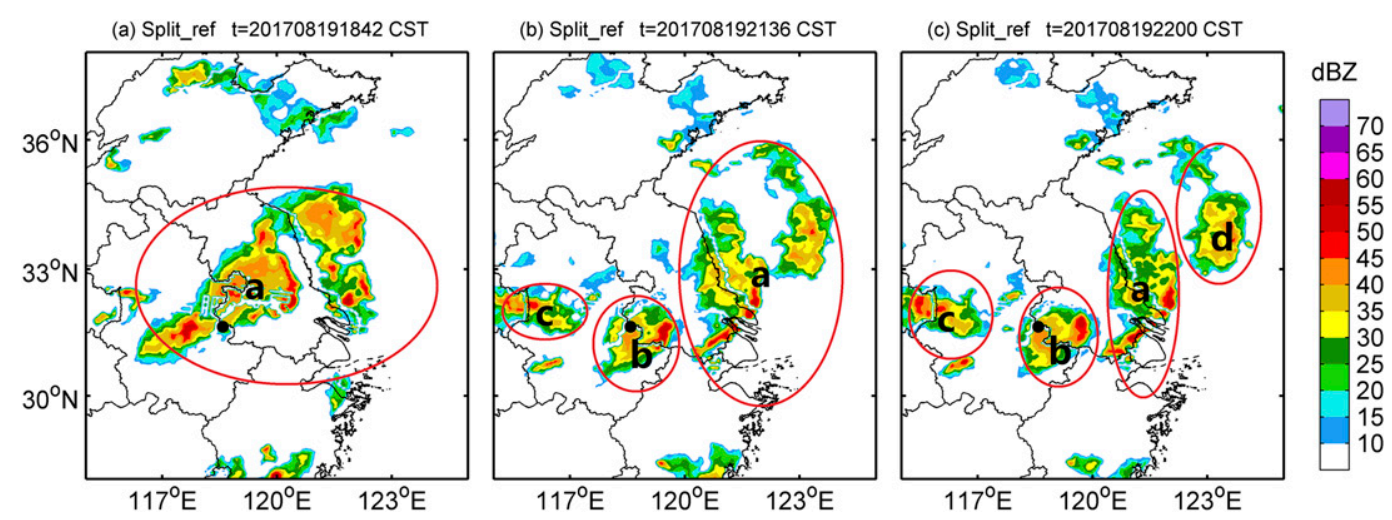

FIG. 5. As in Fig. 4, but for a split MCS event at (a) 1842, (b) 2136, and (c) 2200 CST 19 Aug 2017. 
TABLE 1. The distribution of different types of extreme rainfall events.

\begin{tabular}{lc}
\hline \hline \multicolumn{1}{c}{ Type } & Total \\
\hline Synoptic & $105(51.47 \%)$ \\
Tropical & $5(2.45 \%)$ \\
MCSs & $73(35.78 \%)$ \\
SSSs & $16(7.84 \%)$ \\
Unclassified & $5(2.45 \%)$ \\
Total & $204(100 \%)$ \\
\hline
\end{tabular}

MCSs or SSSs were considered as an unclassified type. Specifically, an extreme rainfall event was arranged into unclassified type when there was no radar echo or any system in the area over its duration, or when systems and rain gauges did not seem to match.

For each archetype, two indicators including duration and total rainfall value were used to characterize extreme rainfall events. When an extreme rainfall event was identified, the duration was defined as the length of the event in hours, and the total rainfall value was referred to as the total precipitation over the duration. For those cases in which the event included more than one station, the precipitation and spatiotemporal features for the most extreme rainfall-occurrence station were applied to represent the event. Thus, in the following analysis, only the stations that reported the most extreme rainfall occurrence are included, regardless of whether the event included more than one station.

\section{Spatial and temporal characteristics}

Between 2016 and 2017, 204 cases over the study area were identified and classified (see Table 1). It was found that synoptic systems were the dominant causes among all the cases, accounting for more than $50 \%$ during the research period. Additionally, there were more than $35 \%$ and $7 \%$ of the events caused by MCSs and SSSs, respectively. These results suggest that nonsynoptic systems are also nonnegligible in their association with extreme rainfall. The rest of the cases were shared equally by tropical cyclones and unclassified scenarios, which affirms similar results with the observations from 2011 to 2015 over the same domain (L16).

Table 2 shows the number of events arranged into each of the synoptic and MCS subclassifications. Consistent with L16, vortices and shear lines induce extreme rainfall events more often than environments with prefrontal conditions. For MCS events, the multiple-MCS pattern was the most extreme-rainfall-producing type, and the next two frequently observed types were disorganized MCSs and BB. Although TL/AS MCSs have been recorded as main extreme-rainfall producers (SJ06), they
TABLE 2. Number of extreme rainfall events associated with the subclassifications of synoptic systems and MCSs.

\begin{tabular}{lrrr}
\hline & Events & $\begin{array}{c}\text { Percent of } \\
\text { synoptic }\end{array}$ & $\begin{array}{c}\text { Percent of } \\
\text { all events }\end{array}$ \\
\hline $\begin{array}{l}\text { Synoptic systems } \\
\text { Front }\end{array}$ & 39 & $37.14 \%$ & $19.12 \%$ \\
Vortex/Shear line & 66 & $62.86 \%$ & $32.35 \%$ \\
Total & 105 & $100 \%$ & $51.47 \%$ \\
& Events & Percent of MCSs & Percent of all events \\
MCSs & & & \\
TL/AS & 8 & $10.96 \%$ & $3.92 \%$ \\
BB & 17 & $23.29 \%$ & $8.33 \%$ \\
LS & 2 & $2.74 \%$ & $0.98 \%$ \\
PS & 5 & $6.85 \%$ & $2.45 \%$ \\
TS & 4 & $5.48 \%$ & $1.96 \%$ \\
Multiple MCSs & 19 & $26.03 \%$ & $9.31 \%$ \\
Disorganized & 18 & $24.65 \%$ & $8.83 \%$ \\
Total & 73 & $100 \%$ & $35.78 \%$ \\
\hline
\end{tabular}

play a less important role in this study. Moreover, the overall percentage of other MCS types was relatively low. Among the three linear MCSs with TS, PS, and LS structures, TS systems generated more events than LS archetypes, and a comparable number to PS MCSs. This may result in part from the faster propagation of TS systems (PJ00), which leads to less total rainfall to certain regional areas.

Figure 6 displays the spatial distribution of the total rainfall values and average hourly precipitation for MCS events (Figs. 6a,c) and other types (Figs. 6b,d), which reveals different precipitation characteristics among different types. First, different categories had their own unique preferred total rainfall maxima. For example, the highest rainfall of MCS events $(>180 \mathrm{~mm})$ occurred along the eastern coast of China (Fig. 6a). The rainfall declined gradually toward western, northern and inland areas, with a second rainfall maximum along the southern coast $(>140 \mathrm{~mm})$ and near the middle and lower reaches of the Yellow River and the Yangtze River $(>100 \mathrm{~mm})$. Although there were sparse areas of high precipitation $(>160 \mathrm{~mm})$ in the northeast, large high rainfall bands were less likely to occur. Conversely, a maximum of strong rainfall for synoptic events $(>240 \mathrm{~mm})$ was located through east-central China, while the rainfall intensity was weak to both eastern and western sides of the high rainfall maximum (Fig. 6b). Unlike the features of total precipitation, Sichuan basin and the northeast region reported a high average hourly rainfall in both MCS events and other types (Figs. 6c,d), which is probably associated with the southwest vortex (Tao and Ding 1981; Chang et al. 1998) and northeast China cold vortices (Zhao and Sun 2007). More importantly, except for two pronounced high values in Jiangsu and the east 

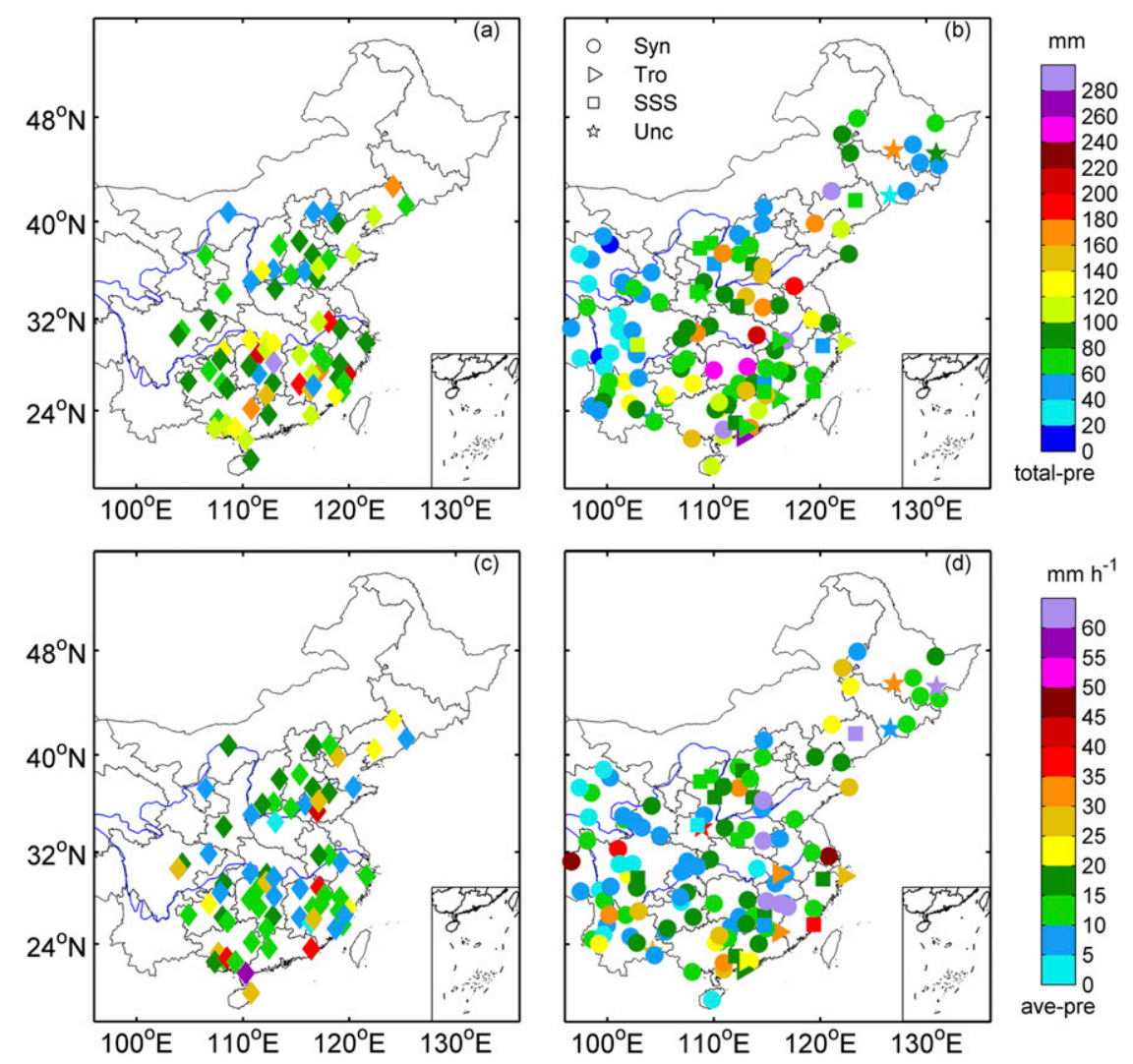

FIG. 6. Spatial distribution of the (top) total rainfall values and (bottom) average hourly rainfall for (a),(c) MCS events and (b),(d) other types. For each event, only the station with the most extreme rainfall occurrence is plotted. The blue lines denote locations of the Yellow River (north) and the Yangtze River (south).

of the Tibetan Plateau ( $>40 \mathrm{~mm} \mathrm{~h}^{-1}$, Fig. $\left.6 \mathrm{~d}\right)$, it is noticeable that the average rainfall intensities for othertype events are comparable with MCS types (Fig. 6c). Since MCS events may have both high rainfall totals and relatively intensive hourly precipitation, which arguably have more potential to cause negative impacts to life and property, the dominant cases in this study are therefore MCS types.

\section{a. Spatial distribution}

For MCS events, the geographical frequency distribution is shown in Fig. 7. To plot this figure, the study area $\left(17^{\circ}-55^{\circ} \mathrm{N}, 96^{\circ}-106^{\circ} \mathrm{E}\right)$ is first divided into a $20 \times 19$ grid of $2^{\circ} \times 2^{\circ}$. The frequency is then calculated for each $2^{\circ} \times 2^{\circ}$ gridpoint area and interpolated into $0.4^{\circ}$ grid boxes. Although the integrated frequency distribution, compared to the distributions in 2016 and 2017, is missing at some locations due to the use of the interpolation method, the high-frequency areas of MCS events remain relatively intact. Overall, there are four main regions of high frequency recognized: South China (I), the area south of Yangtze River (II), downstream of
Yangtze River (III), and Huanghuai Valley (IV). In general, the frequency of extreme precipitation is notably high in southern areas and lower in the north, and there were several maxima in these regions. Specifically, there was a high-frequency maximum located south of Fujian in Region I, accounting for about $5 \%$ of all MCSrelated events. This maximum includes areas along the coastline and over Mountain Wuyi, and may be affected by the East Asian summer monsoon (hereafter EASM), synoptic southerly low-level jet, the boundary layer flow over land and land-sea breeze circulations (e.g., Chen et al. 2014, 2015). In Region II, a high-frequency maximum was observed southwest of Hunan, with the extreme rainfall frequency lower than $4 \%$. This maximum appeared near the middle reaches of the Yangtze River, and seems to be associated with the combination of EASM and the low-level vortex or shear line that occurs in the east of the Tibetan Plateau (e.g., Hu and Pan 1996; Sun et al. 2004). The third and easternmost maximum, which was also roughly isolated, was located downstream of the Yangtze River. A high-frequency of extreme rainfall events was observed north of Zhejiang 

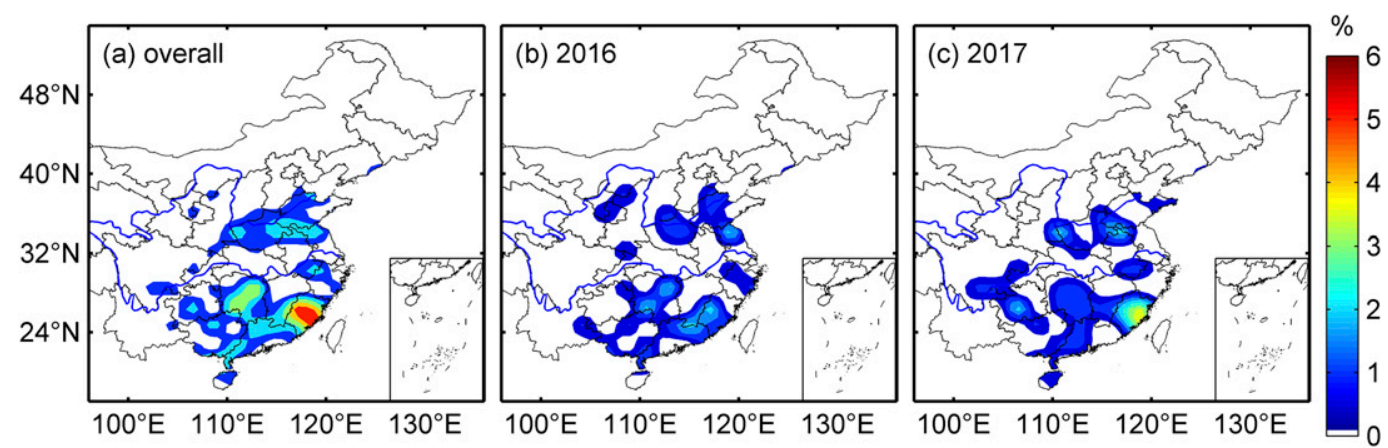

FIG. 7. Geographical distribution of the frequency for MCS-type events: (a) overall, (b) 2016, and (c) 2017. For each event, the most extreme rainfall-occurrence station represents the location of the event. Note that the frequency indicates the number of the events in each $2^{\circ} \times 2^{\circ}$ gridpoint area divided by the total number of MCS events.

and south of Anhui. The precipitation in this area was generally related to EASM, the movement of western Pacific subtropical high (WPSH), South Asian high, and the mei-yu front (e.g., Yao et al. 2007). The last main region of MCS events was mainly influenced by EASM, the movements of WPSH and shortwave troughs (e.g., Bao 2007). A maximum with relatively high frequency in this region was observed north of Henan and southwest of Shandong. Besides these four main regions, there were several other zones in which MCS-related extreme rainfall events occurred, such as Sichuan basin and North China. Some similar results have also been documented in previous studies over China (e.g., Bao 2007; Tu et al. 2010, Zheng et al. 2016).

As discussed above (Table 2), there were four additional frequent extreme-rainfall-producing MCS types, namely TL, BB, multiple, and disorganized MCSs. The spatial distribution of these four types resembles the overall frequency distribution closely. However, different types do cluster in their own preferred regions (Fig. 8). For example, BB and disorganized MCSs were associated with a great proportion of extreme rainfall over South China, Yunnan-Guizhou Plateau, Sichuan basin, and Huanghuai basin (Figs. 8b,g). In contrast, TL systems played a large role in the middle reaches of the Yellow River (Fig. 8a), whereas multiple MCS was the most common MCS type in South China and the middle reaches of Yangtze River (Fig. 8f). Moreover, apart from a high-frequency maximum of disorganized MCS events located in Hainan, the distribution for BB and disorganized MCS events was more even. In contrast to the MCS types responsible for more events, the other MCS types
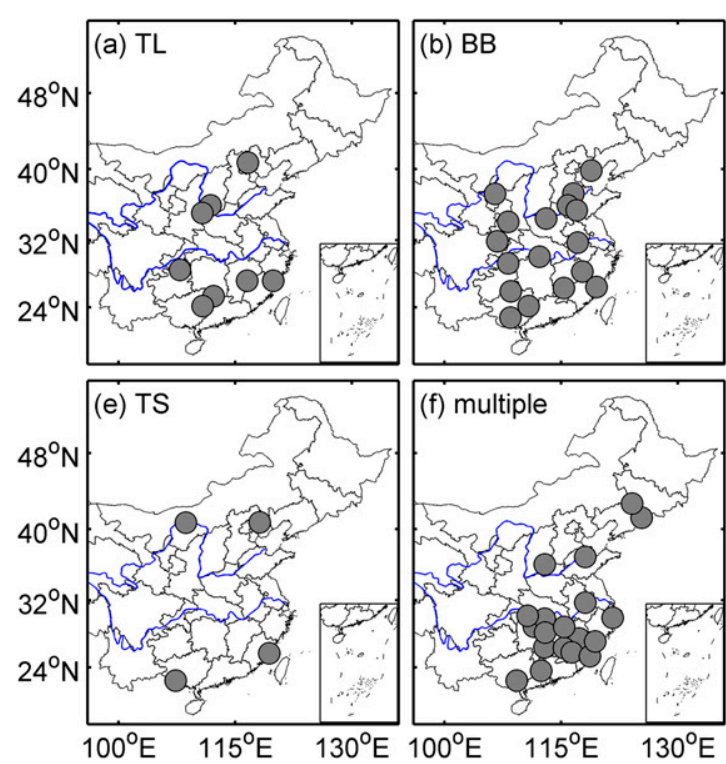
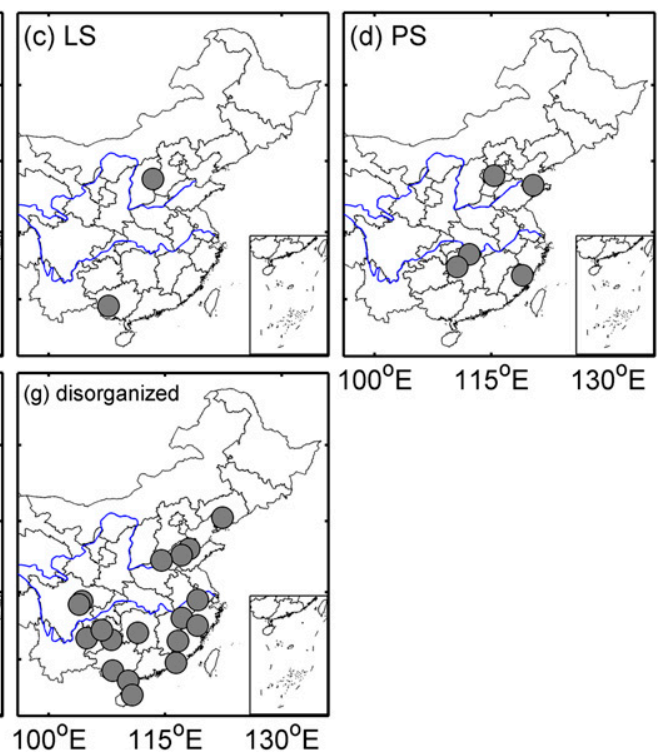

FIG. 8. Spatial distribution for seven types of MCS events: (a) TL, (b) BB, (c) LS, (d) PS, (e) TS, (f) multiple MCSs, and $(\mathrm{g})$ disorganized MCS. 

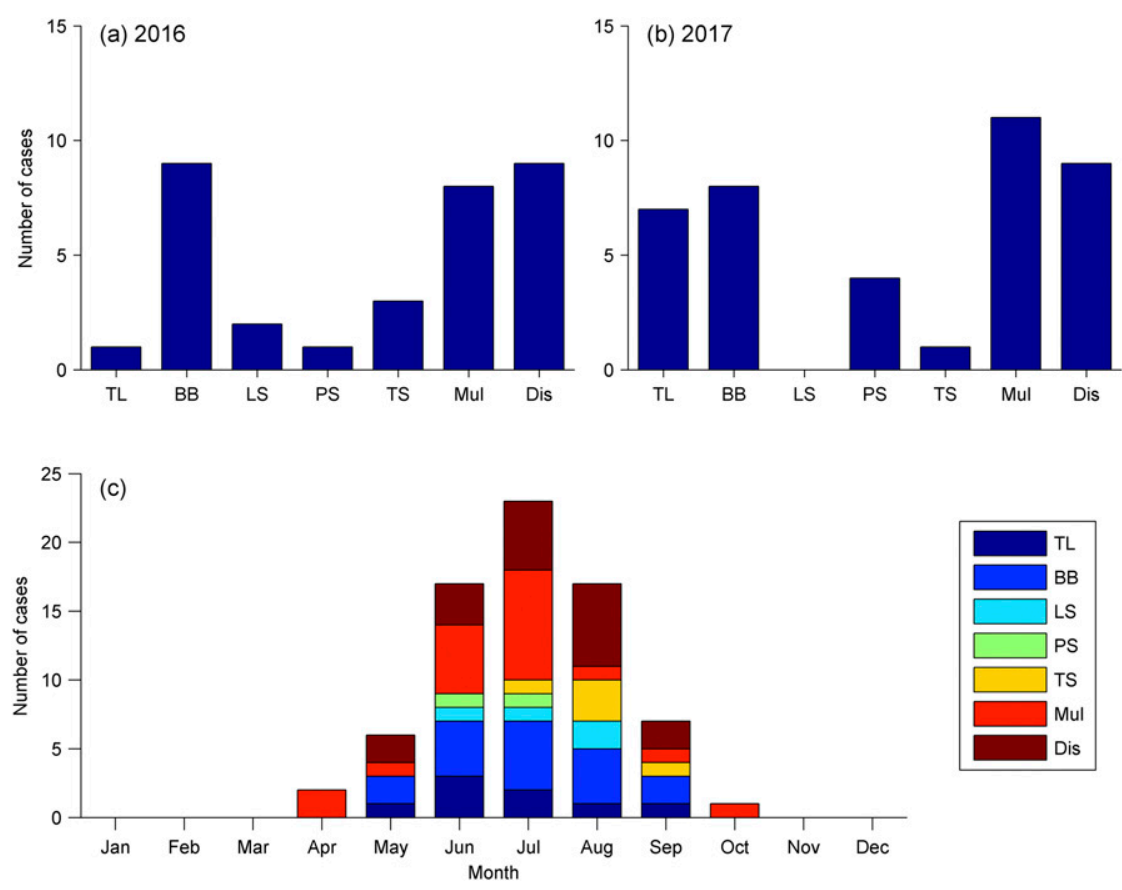

FIG. 9. Annual and monthly numbers for MCS events.

contributed less to the event-concentrated areas. In detail, both PS and TS events were located north of the middle and lower reaches of Yellow River and south of the middle and lower reaches of Yangtze River (Figs. 8d,e). The two observed LS systems occurred downstream of Yellow River and Southern Yunnan (Fig. 8c). With the caveat that with only 2 years of data, there may be substantial year-to-year variability in some of these subclassifications that has not been captured here.

\section{b. Interannual and monthly variability}

Figure 9 displays the annual and monthly numbers of MCS-related events, in which we can observe considerable variability within the sample. From 2016 to 2017, although the events caused by TL, PS and multiple MCS increased, the events caused by BB, TS, and LS decreased while disorganized MCS types kept almost the same level. Regarding the monthly variability, extreme rainfall events occurred most often in July, followed by June and August. The monthly distribution of individual MCS subclassifications was consistent with the overall distribution. BB and multiple MCS events were more common in July, with fewer events occurring in other months. The peak monthly frequency of TL type was observed in June, whereas the highest frequency of TS and disorganized MCS events were in August. From April to October, the number of other MCS types increased first and then decreased, while the multiple-MCS type reduced in May, followed by an increase until July, and then decreased.
For comparison with MCS types, the numbers of other types of events between 2016 and 2017 are also illustrated (Fig. 10). Unlike different types of MCSs, the annual characteristics of other types are almost the same. Specifically, events associated with vortices or shear lines overwhelmed others, with more than 30 cases occurring each year. Frontal events were also main rainfall makers, with more events in 2017 ( 23 cases) than 2016, while tropical systems, SSS and unclassified scenarios produced less than 10 cases annually. Moreover, the general monthly changes of other types were similar with those of MCSs, wherein June, July, and August were the most active precipitation months. From the type point of view, frontal cases had the most frequent occurrence in June and were more likely to appear over more months. Vortex or shear line type, another category that occurred in multiple months, dominated the cases in August. Among the rest, tropical events occurred in August and October, SSS-related events appeared from July to October, while unclassified types generated the same number of events from May to October excluding June.

In addition to overall numbers, the annually and monthly spatial distribution of MCS events are also explored. On one hand, there was an obvious annual variation in location of the events (Fig. 11). In 2016, the events were concentrated on both the north and south side of Huaihe basin, with relatively few events to the west of $105^{\circ} \mathrm{E}$. In 2017 , however, the extreme rainfall 

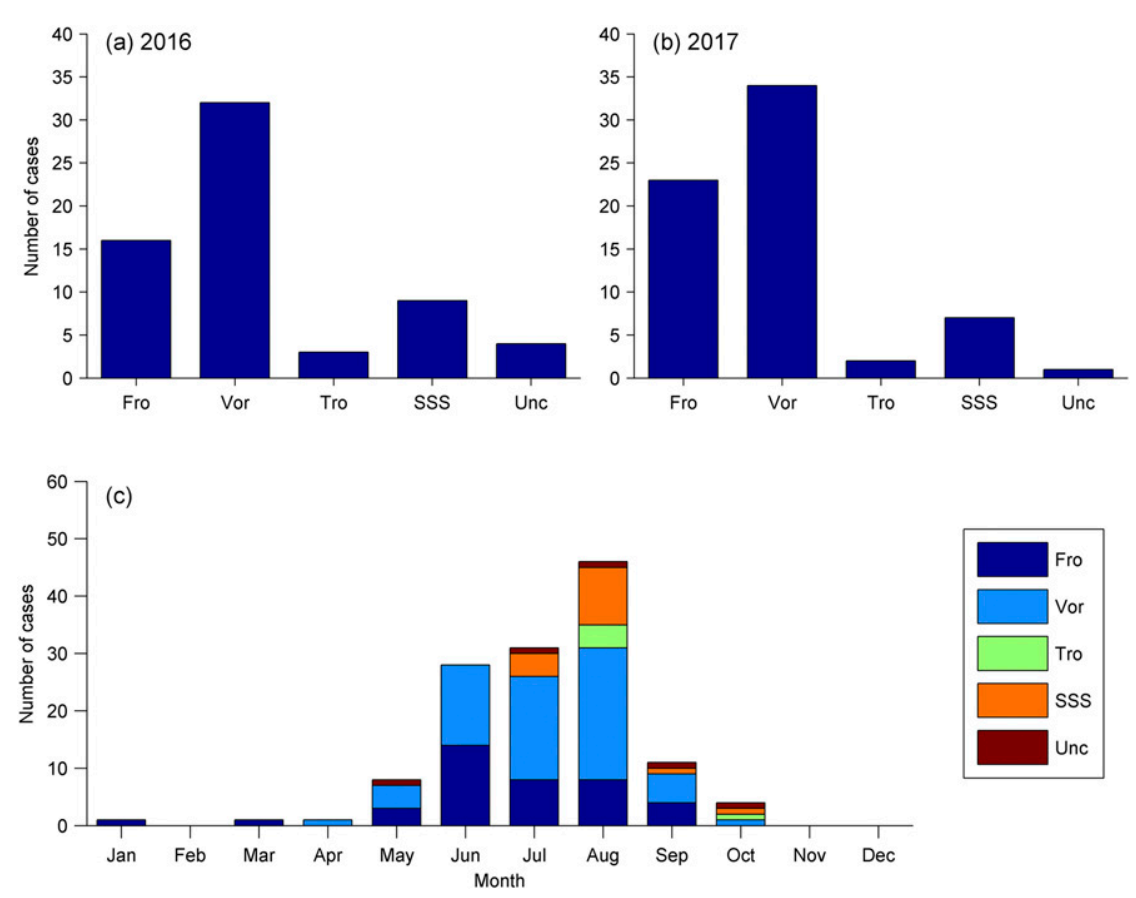

FIG. 10. As in Fig. 9, but for annual and monthly numbers of other types.

events were relatively balanced over the event-concentrated areas. An apparent modification was also observed for the events' monthly spatial distribution (Fig. 12). As early as May, a pronounced high-frequency region appeared over the northwestern Yunnan-Guizhou Plateau and the southern part of East China (Fig. 12a). After May, the high-frequency maximum moved gradually toward the northern part of China, with most cases occurring in July, and the northernmost region's occurrence remained north of $45^{\circ} \mathrm{N}$ until August (Figs. 12b-d). In September, the high-frequency maximum returned to south of $30^{\circ} \mathrm{N}$ (Fig. 12e). This modification is mainly because of EASM and WPSH (e.g., Xu and Zipser 2011). Before June, the ridgeline of WPSH is located south of $20^{\circ} \mathrm{N}$. With the onset of EASM, the warm and moist southwesterly flow interacts with the cold air near the northern boundary of WPSH, creating a favorable environment for extreme rainfall events. Due to the northward movements of WPSH and EASM during midsummer, the favorable regions move in phase, with the rainbands migrating northward correspondingly. At the beginning of September, the ridgeline of WPSH and EASM begins to recede, and the rain belt moves southward.
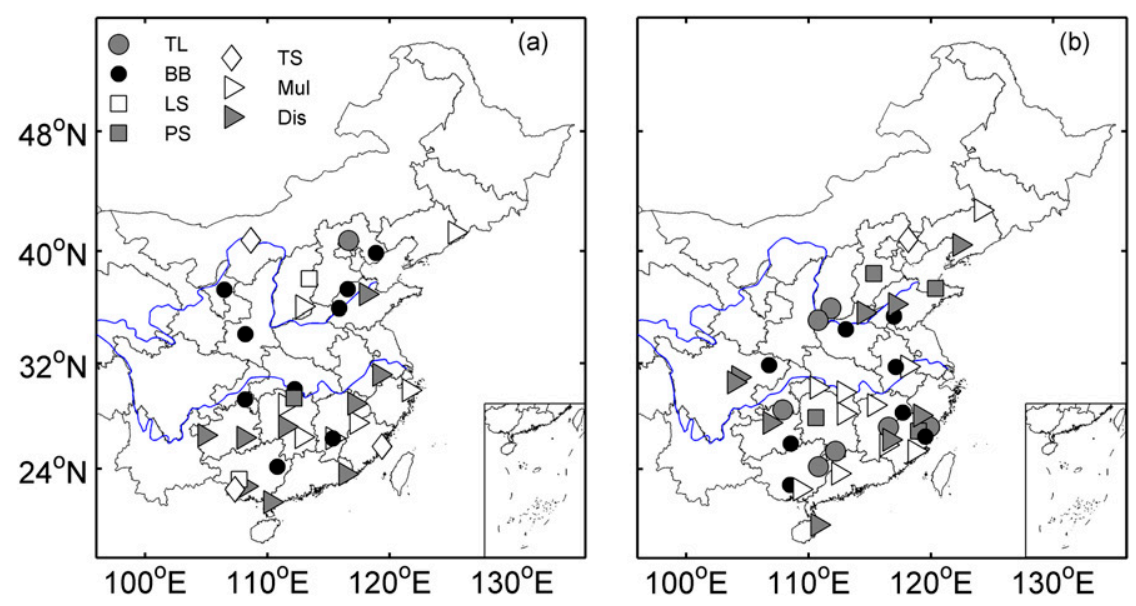

FIG. 11. Locations of MCS extreme rainfall events in (a) 2016 and (b) 2017, by storm type. 

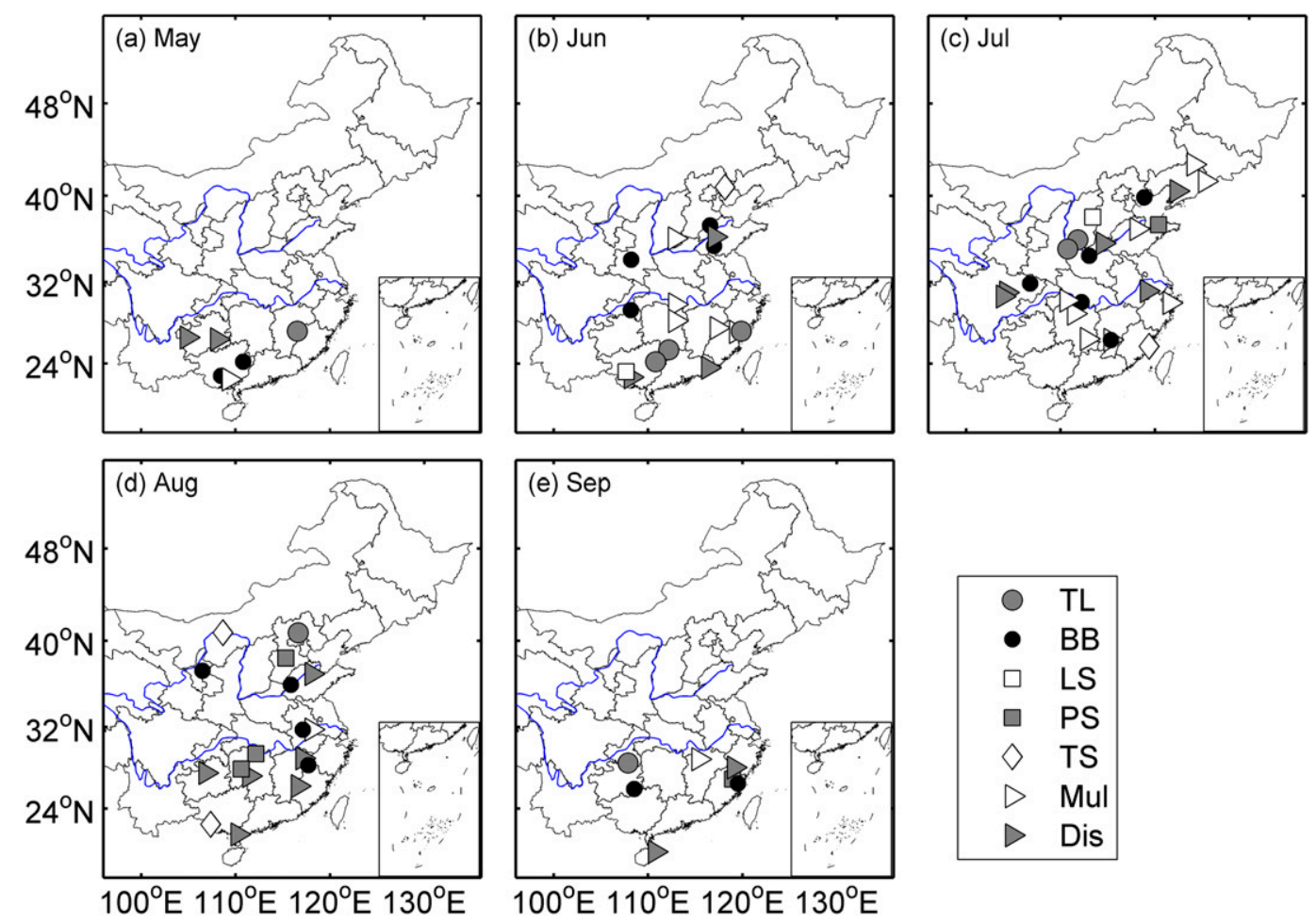

FIG. 12. As in Fig. 11, but for the monthly spatial distribution of MCS extreme rainfall events from May to August.

\section{c. Diurnal cycle}

To understand the driving forces behind the convection and to ascertain its predictability, it is also crucial to know the diurnal cycles of the events, namely the onset time, peak rainfall time, and end time. In Fig. 13, three key stages of the events are presented by storm type. Even though each type of events could initiate, rain the most, and dissipate at almost any time of the day, relatively few events began between 0800 and 1400 CST. However, a large number of events occurred from afternoon (1500 CST) to early evening hours (2000 CST), with the highest frequencies of peak rainfall time around 1700 CST (Fig. 13b) and an end time at 2100 CST (Fig. 13c). This result is different from the nocturnal characteristics of precipitation in $\mathrm{Xu}$ and Zipser (2011). The contrast is contributed to different definitions of precipitation events, the duration of precipitation, the area where precipitation occurs, and whether precipitation occurs during premonsoon or postmonsoon period (e.g., Yu et al. 2007; Chen et al. 2009; Chen et al. 2009; Jiang et al. 2017).

Considering the diurnal frequency by storm type, there were unique diurnal characteristics for some types. For example, TL, TS, and disorganized MCS events had strong diurnal cycles, corresponding closely to the overall distribution. On the contrary, each rainfall stage for BB and multiple MCS types had a wide distribution.
Regarding LS events, the highest frequency of initiation and peak rainfall stages occurred at 2200 CST and 0500 CST, respectively, while the rain ended at 0200 or 0700 CST. As for PS type, heavy rain began predominantly at 1700 or 1800 CST, peaked between night and early morning and ended at various hours of the day. Although these are interesting findings, it is important to note that due to the small sample of TS, LS, and PS events, the results may not be generalizable.

We also choose to analyze the diurnal distribution for the actual extreme rainfall observations. Similar to the distribution of peak rainfall, the times when the precipitation identified to exceed the extreme rainfall threshold were mostly observed from late afternoon to evening (Figs. 14a,b). The threshold-exceeding precipitation usually lasted for $1-5 \mathrm{~h}$, with the duration between 1 and $2 \mathrm{~h}$ being more common while durations longer than $3 \mathrm{~h}$ were infrequent (Fig. 14c). Among all the MCS categories, extreme precipitation of TS and LS types maintained for a short period of time, and slightly longer-duration extreme precipitation occurred in the multiple-MCS type.

\section{Precipitation features and environmental conditions}

Although all seven MCS types are capable of producing extreme rainfall in certain cases, it is still a question as to 

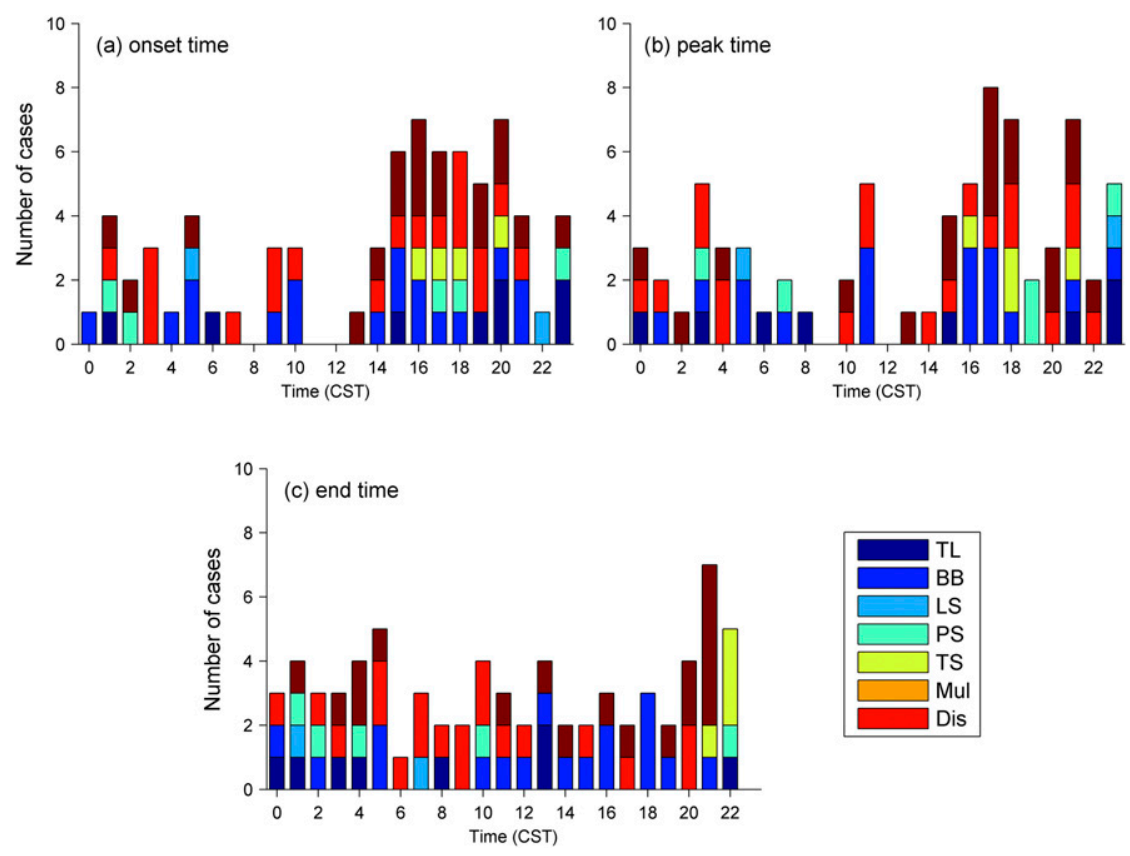

FIG. 13. Histogram of (a) onset time, (b) peak time, and (c) end time for MCS extreme rainfall events.

which types tend to have the most potential for negative impacts to life and property. As shown in section 4, precipitation characteristics are useful statistics for estimating these effects. Thus, in section 5a, we first study the precipitation characteristics of various types of MCS events. Furthermore, to better understand the processes at work in multiple-MCS extreme rainfall events, we observe the prevailing atmospheric conditions in section $5 \mathrm{~b}$.
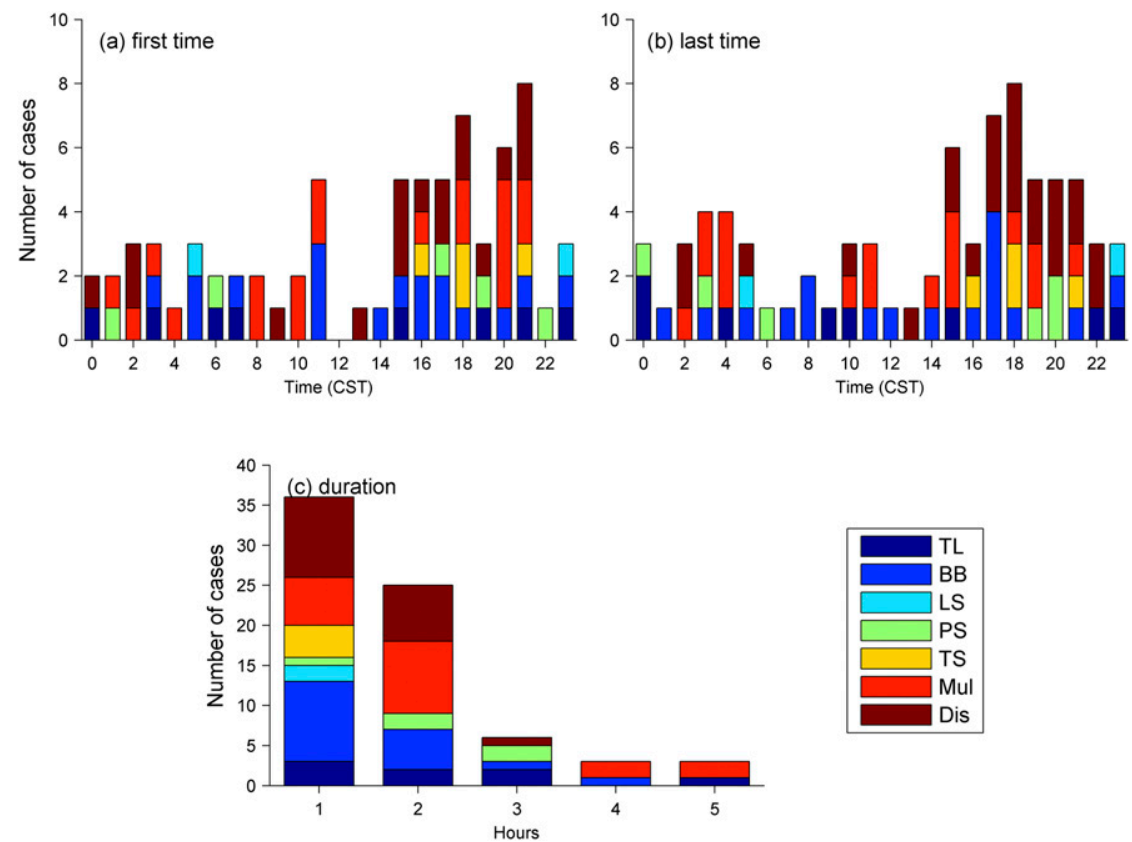

FIG. 14. Histogram of (a) first time, (b) last time, and (c) duration when the precipitation identified to exceed the extreme rainfall threshold. 
TABLE 3. Average duration (h) of MCS-related extreme rainfall events, by storm type. The duration is simply the amount of time between the event's onset and end time.

\begin{tabular}{cccccccr}
\hline \hline Type & TL & BB & LS & PS & TS & Multiple MCS & Disorganized \\
\hline Duration & 8.13 & 7.59 & 3.50 & 5.80 & 4.75 & 12.79 & 5.06 \\
\hline
\end{tabular}

\section{a. Overall rainfall features}

In addition to the total rainfall and average hourly rainfall discussed in section 4 , duration is another useful piece of information that can give insight into different influences of events. The average duration for each type of MCS-related extreme rainfall events is shown in Table 3. The duration for a certain event, in this study, is simply the amount of time between the event's earliest onset and latest end time of all extreme precipitation stations. This definition does not necessarily imply that the rainfall was falling throughout the entire duration; however, since we have specified the discontinuity for a single case in section 2 , and there were few discontinuities in most of the precipitation events, it is rational to say that the duration in this study approximates the amount of time when precipitation occurred. As displayed in Table 3, multiple-MCS events had the longest average duration, followed by TL and BB types, while LS, TS, and disorganized-MCS events had shorter duration. Although PS cases also had relatively short durations in an average sense, some were noted to last for about $6 \mathrm{~h}$

\section{b. Environmental properties of multiple-MCS events}

As discussed above, it was found that multiple-MCS events have a longer duration than other types over East China. Since TL/AS, BB, LS, PS, and TS cases have been fully analyzed in previous work (e.g., Parker and Johnson 2000; Parker 2007; French and Parker 2008; Schumacher and Johnson 2009; Smith et al. 2009; Wang and Cui 2012; Zheng et al. 2013), we chose to further study the premultipleMCS environment.

To study the mesoscale conditions, several variables were taken from NCEP Climate Forecast System, version 2 (CFSv2), reanalysis to do a composite analysis. The variables include horizontal wind speed, air temperature, geopotential height, and water vapor mixing ratio at a horizontal resolution of $0.5^{\circ} \times 0.5^{\circ}$, a temporal resolution of $1 \mathrm{~h}$, and specified at a few certain levels.
The former three variables are distributed at 1000, 850 , 700,500 , and $200 \mathrm{hPa}$, and the mixing ratio is provided at $925,850,700$, and $500 \mathrm{hPa}$. Although coarse vertical resolution limits the analysis of buoyancy and instability, the selected variables are at a greater number of vertical levels compared to other CFSv2 variables. Moreover, the longer time resolution of the CFSv2 reanalysis makes it more favorable to analyze environmental features at specific times than other reanalysis datasets.

Additionally, compensating for the relatively few vertical layers of CFSv2 reanalysis data, a total of 15 rawinsondes related to multiple-MCS events were also used for the composite analysis. The online rawinsonde data maintained by the Department of Atmospheric Science of University of Wyoming (available at http:// weather.uwyo.edu/upperair/sounding.html) were also utilized in previous studies (e.g., Meng et al. 2013). For a single event, the rawinsonde gauge nearest the most extreme rainfall-occurrence station was used for analysis. Further, due to coarse temporal resolution, the launch time closest to the peak rainfall time was used in the analysis.

Prior to further study, multiple-MCS events were classified into early-maturing and late-maturing (Table 4) categories. The early-maturing type refers to the cases with the occurrence of peak rainfall before the midpoint of the duration, whereas cases with peak rainfall occurrence later than the midpoint were defined as the late-maturing type. In addition, in order to reduce the contamination caused by different geographic locations, the events with higher altitude or relatively isolated location of the most extreme rainfall-occurrence point (red points in Fig. 15) were eliminated. Consequently, there were 11 early-maturing cases and 4 late-maturing cases used to perform each composite analysis. We suggest the only four cases are likely a poor sampling for the late-maturing composite. Therefore, in section 6 , the environments of two individual processes were compared to assess whether the differences between the composites are credible.

TABLE 4. Numbers of early-maturing and late-maturing events for each type.

\begin{tabular}{lcccccrr}
\hline \multicolumn{1}{c}{ Type } & TL & BB & LS & PS & TS & Multiple MCS & Disorganized \\
\hline Early maturing & 6 & 14 & 2 & 2 & 3 & 13 & 6 \\
Late maturing & 2 & 3 & 0 & 3 & 1 & 3 \\
\hline
\end{tabular}



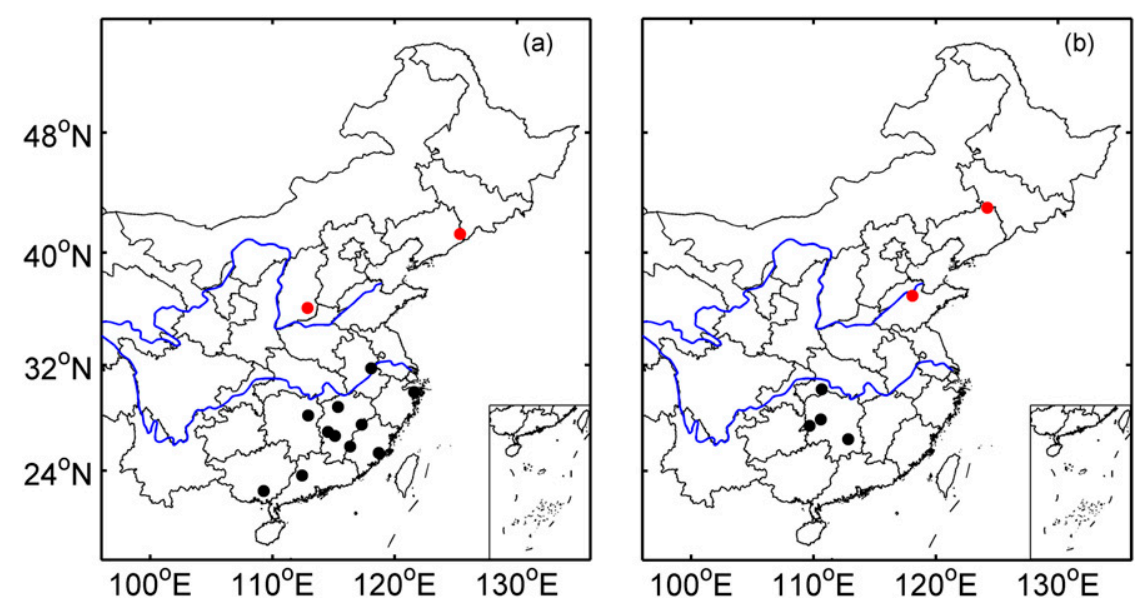

FIG. 15. Distribution of the most extreme rainfall-occurrence gauges for (a) early-maturing and (b) late-maturing events.

Figure 16 shows the composite analysis of the environment at $850 \mathrm{hPa} 3 \mathrm{~h}$ before the onset of earlymaturing and late-maturing events. From the perspective of dynamic conditions, the difference between the two multiple-MCS types is associated with the low-level convergence. Before the occurrence of early-maturing cases, there was obvious convergence implying uplifting above the most extreme rainfall-occurrence point. Such dynamic structure was favorable to trigger precipitation. Comparatively, there was much stronger convergence in the late-maturing composite at different locations, but not near the center point. In addition, for both earlymaturing and late-maturing events, the prevailing winds were from the southwest at this level with a low-level jet extending from the southwest of the domain's center to its east or northeast. That the low-level jet is a common condition for the formation of rainfall extremes is consistent with previous studies of heavy rainfall (e.g.,
Nicolini et al. 1993; LeMone et al. 1998; Buzzi and Foschini 2000; Lin et al. 2001; Chen et al. 2005). One main difference between the wind fields was more southerly component upwind of the most extreme rainfall-occurrence point in the early-maturing cases. Thermodynamic factors are also important for influencing extreme rainfall. Distributions of pseudo equivalent potential temperature $\left(\theta_{\mathrm{se}}\right)$ were also plotted for early-maturing (left) and late-maturing (right) events in Fig. 16. There was high $\theta_{\text {se }}$ region concentrated on the southwest side of the domain. Along with the low-level strong wind, there was strong warm-air advection in both categories. Corresponding to the stronger wind, there was higher $\theta_{\mathrm{se}}$ in the late-maturing composite, but there was a tighter $\theta_{\text {se }}$ gradient in the early-maturing events. As time grew, the warm advection increased in the late-maturing cases and decreased in the earlymaturing cases (not shown). Thus, it is hypothesized
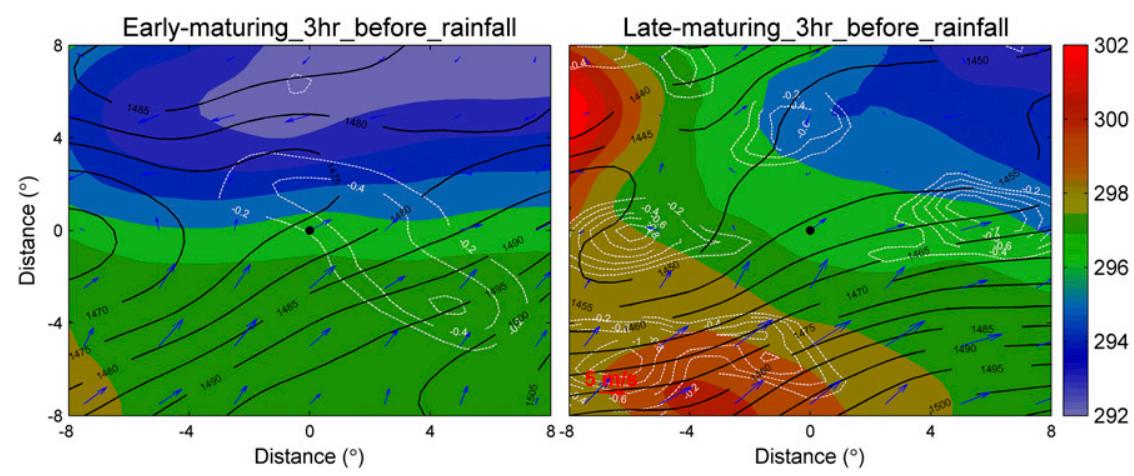

FIG. 16. Composite 850-hPa environment for (left) 11 early-maturing and (right) 4 latematuring multiple MCS events 3 hours before precipitation. Plotted are geopotential height [black contours, geopotential meters (gpm)], divergence less than 0 (white contours, $10^{-5} \mathrm{~s}^{-1}$ ), pseudo equivalent potential temperature $\theta_{\text {se }}$ (shaded, $\mathrm{K}$ ), and wind speed (vectors, $\mathrm{m} \mathrm{s}^{-1}$ ). The center of the domain (black point) is the most extreme rainfall-occurrence point. 
Skew-T / log-P Diagram
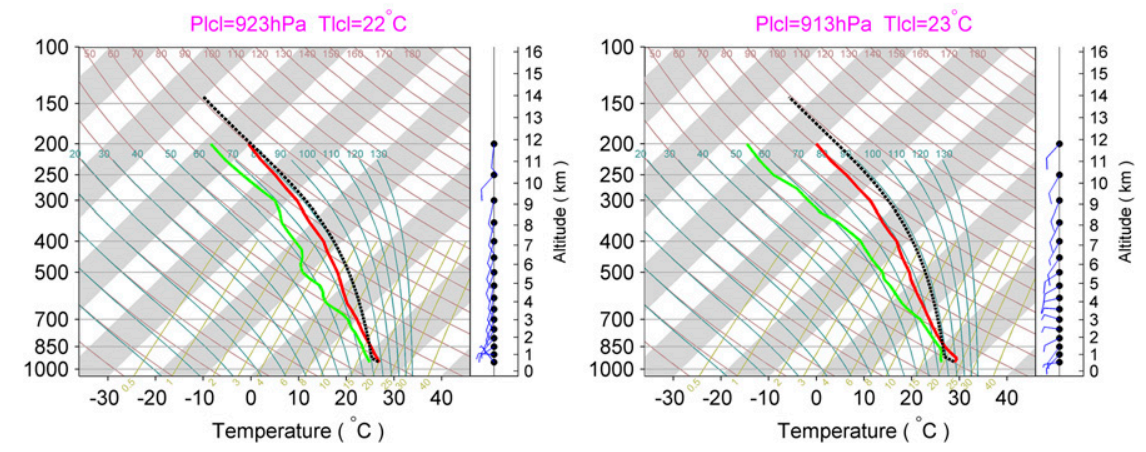

FIG. 17. Composite soundings for (left) early-maturing and (right) late-maturing multiple MCS events at the beginning of precipitation. The red lines represent the temperatures throughout the atmosphere, the green lines represent the dewpoint temperatures, and the black dotted lines show the 950-hPa-based parcels' temperatures.

that the precipitation of early-maturing events is caused by upward motion and warm features of the preenvironment, while the late-maturing precipitation depends on the warm-air transportation after the event onset. Moreover, the $\theta_{\mathrm{se}}$ lines gradually slope downward with height below $700 \mathrm{hPa}$ (not shown), indicating that low-level atmosphere is unstable, which is an important condition for development of extreme rainfall (e.g., Huang et al. 2008; Chen et al. 2015).

Various features of the 15 selected rawinsondes were used to construct the composite sounding at the time when precipitation began. As mentioned, due to coarse temporal resolution, it was difficult to find the launch times that same as the beginning of the rainfall. Therefore, the time closest to the onset of a certain case was considered as the start of the precipitation. Concerning the precipitation modes, the sounding of the earlymaturing cases showed a moister environment below $850 \mathrm{hPa}$ and above $400 \mathrm{hPa}$, as dewpoint depression was generally greater than the late-maturing cases at these levels (Fig. 17). Since the air was moister at the low level, less lifting was required for parcels in the early-maturing cases to reach saturation. This feature was manifested in the lifting condensation level (LCL). Although the temperatures of the two categories were almost the same at the average LCL, the average LCL for the earlymaturing cases was lower.

Four other properties investigated for the early-maturing and late-maturing cases were surface-based convective available potential energy (SBCAPE), surface-based convection inhibition (SBCIN), mixing ratio at the mean mixed layer, and precipitable water for the entire sounding. In ingredients for extreme rainfall, CAPE and CIN are two measurements of instability, in which CAPE is related to updraft strength in thunderstorms while CIN represents the energy that must be overcome for the initiation of convection. As Figs. 18a,b show, the late-maturing cases had more average SBCAPE (about $1200 \mathrm{~J} \mathrm{~kg}^{-1}$ more) than the early-maturing cases, but they also needed to overcome greater SBCIN (nearly $10 \mathrm{~J} \mathrm{~kg}^{-1}$ more) before
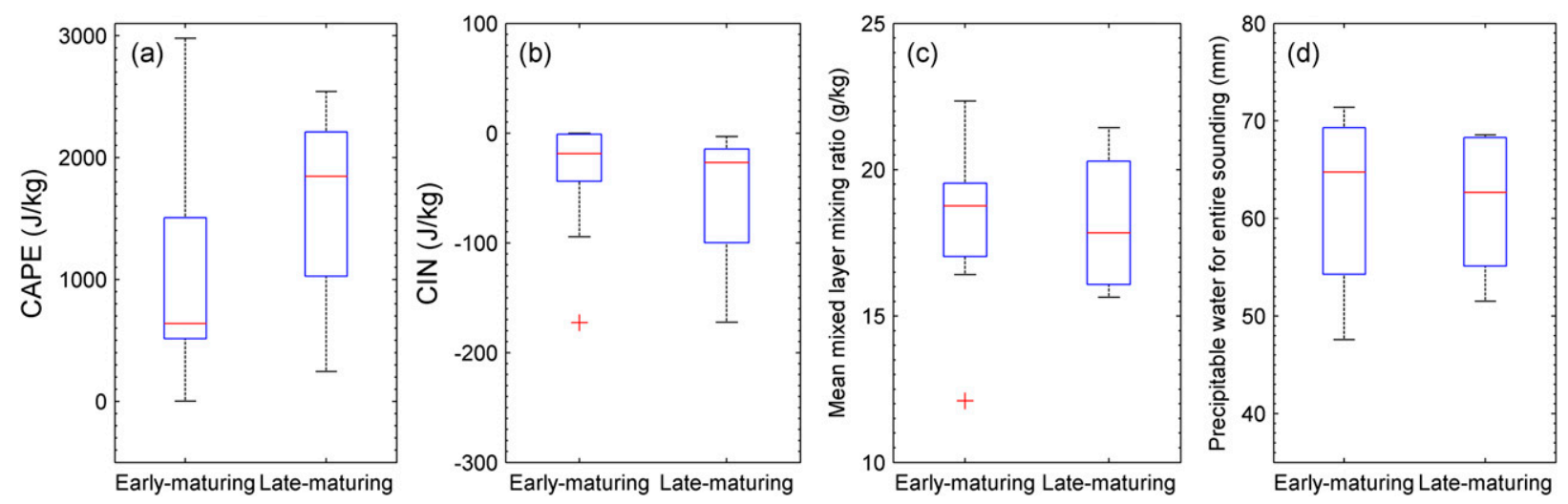

FIG. 18. Box-and-whisker plot of (a) CAPE $\left(\mathrm{J} \mathrm{kg}^{-1}\right)$, (b) CIN $\left(\mathrm{J} \mathrm{kg}^{-1}\right)$, (c) mixing ratio at the mean mixed layer $\left(\mathrm{g} \mathrm{kg}^{-1}\right)$, and (d) precipitable water $(\mathrm{mm})$ for all soundings of early-maturing and late-maturing multiple MCS events. 

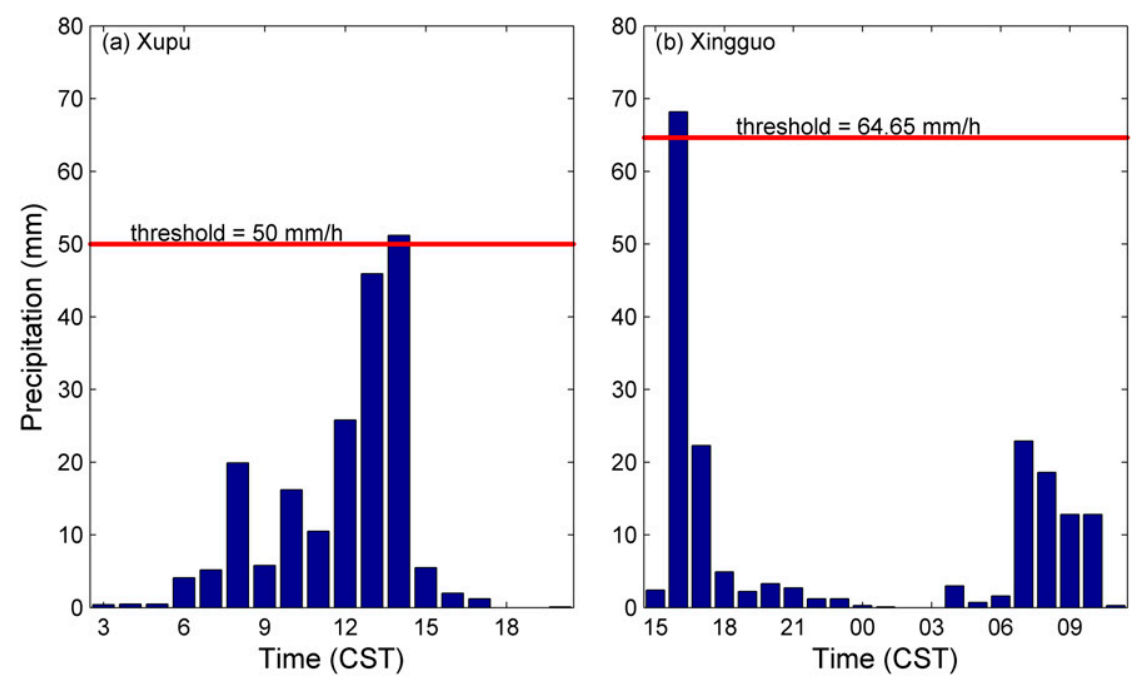

FIG. 19. Time series of precipitation ( $\mathrm{mm}$ ) for the peak rainfall gauge (a) Xupu from the latematuring process between 0300 CST $17 \mathrm{Jul}$ and 2000 CST $17 \mathrm{Jul} 2016$, and (b) Xingguo from the early-maturing process between 1500 CST 17 Jul and 1100 CST 18 Jul 2016.

reaching the average LCL. Furthermore, for the occurrence of extreme precipitation, sufficient moisture is also necessary. The mixing ratio at the mean mixed layer of early-maturing and late-maturing cases were 18.7, $17.6 \mathrm{~g} \mathrm{~kg}^{-1}$, and the precipitable water for entire sounding were 64.5 and $62.4 \mathrm{~mm}$, respectively (Figs. 18c,d). Consistent with the moisture condition discussed above, the early-maturing cases occurred in a moister environment than the late-maturing cases, which was also verified in the Climate Forecast System Reanalysis (CFSR) composite (not shown).

\section{Case studies}

From 17 to 18 July 2016, a multiple-MCS extreme rainfall case happened mainly in Hunan and Jiangxi Provinces. Of interest is that there was successively a late-maturing and another early-maturing process throughout the event, which was counted as two cases within the composites in section 5. During the latematuring process, the rain began at 0300 CST 17 July, peaked at 1400 CST 17 July and ended at 2000 CST 17 July (Fig. 19a). The peak rainfall occurrence was observed in Xupu County (blue diamond in Fig. 20), near the west of Hunan Province. The rain of the earlymaturing process started to fall at 1500 CST 17 July 2017 and ended at 1100 CST 18 July 2017 (Fig. 19b), with the most extreme rainfall occurring at 1600 CST 17 July 2017 in Xingguo, Jiangxi (black spot in Fig. 20).

At 0300 CST 17 July, a belt of stratiform cloud crossed Hunan and Jiangxi, causing sporadic precipitation in the southern part of Hunan Province and the western part of
Jiangxi Province. The cloud belt subsequently moved eastward and developed into a relatively complete convective line, which stayed and resulted in strong local precipitation to most parts of central Jiangxi Province. However, little and intermittent precipitation was observed in Xupu and Xingguo until 0600 CST.

At 0600 CST 17 July, a small convective cell occurred in the western region of Hunan Province (Fig. 20b). By about 0900 CST, a series of fragmented convective cells were triggered and caused severe local rainstorms along the provincial boundary of northern Hunan Province to the east of Guizhou Province (Fig. 20c). These convective cells slowly moved eastward and developed into a convective line around 1300 CST 17 July (Fig. 20d), which directly led to a remarkable amount of precipitation in the Xupu area. It is worth noting that at the same time, there were a new cell generating north of Hunan Province and a system remaining west of Jiangxi Province. The convective line then merged with the two systems and became a $\mathrm{M} \beta \mathrm{CS}$ (meso- $\beta$ convective system) around 1500 CST 17 July (MCS a in Fig. 20e). At the same time, MCS b originated in southern Jiangxi, with the maximum radar reflectivity exceeding $45 \mathrm{dBZ}$ centered at about $115.8^{\circ} \mathrm{W}, 26.5^{\circ} \mathrm{E}$. Afterward, MCS b developed eastward, producing maximum rainfall amount at 1600 CST 17July, which was the main maker of the rainfall extreme. From 1800 CST 17 July onward, MCS $b$ merged with the remnant of MCS a and continued to affect most parts of Jiangxi Province (Fig. 20f). The merged system lasted more than $10 \mathrm{~h}$, kept raining in Xingguo for $7 \mathrm{~h}$ until 0100 CST 18 July. Additionally, at 0400 CST 18 July (Fig. 20g), a northwestern-southeastern 


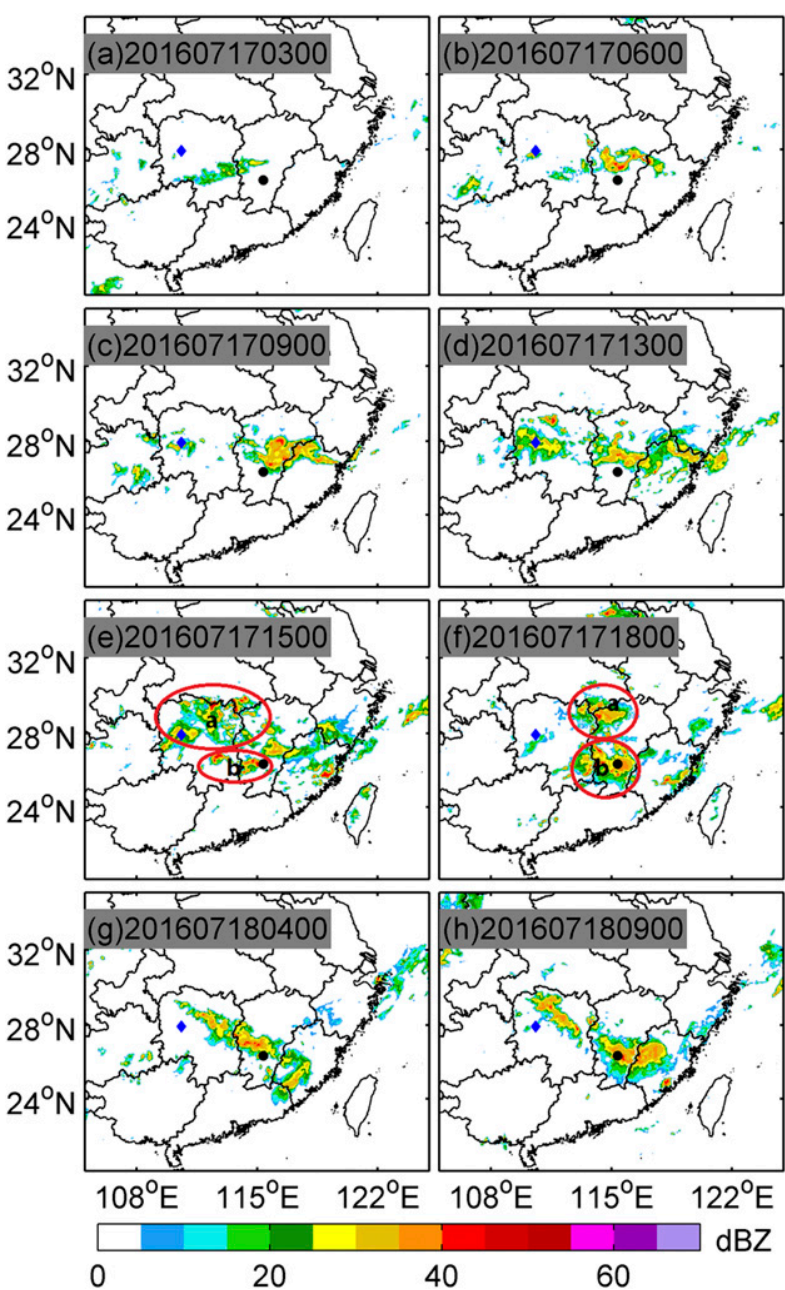

FIG. 20. Composite radar reflectivity (dBZ) from the multipleMCS event at 0300, 0600, 0900, 1300, 1500, and 1800 CST $17 \mathrm{Ju}$ 2016 and 0400 and 0900 CST 18 Jul 2016. All panels use the same map boundary. Moreover, the blue diamond is the location of $\mathrm{Xupu}$, while the black spot is position of Xingguo.

echo band dominated by convective clouds existed from northern Hunan Province to central Jiangxi Province. The clouds subsequently moved toward the southeast. At 0900 CST 18 July (Fig. 20h), the system split during its movement, in which the front-flank split system continued to develop and exert a continuous influence on the northern part of Jiangxi Province. Overall, this event with its wide spatial range and long duration affirmed the main features of a multiple-MCS event.

The environmental conditions of the two individual processes resemble the composites. When observing the difference between the two processes, a corridor of higher warm advection and stronger southerly component is evident in (Fig. 21) the late-maturing process. Additionally, sounding observations on the MCS propagation paths were used to calculate the mesoscale conditions for the individual processes (Fig. 22). Although there was lower precipitable water, higher SBCAPE and mean mixed layer mixing ratio were in place to support the latematuring process (Figs. 23, 24).

\section{Comparison between China and the United States}

In previous studies, many statistics on MCS-related extreme rainfall events were focused on the United States, whereas the corresponding research in China is relatively lacking. Although these two regions are in roughly same latitude in the Northern Hemisphere and both have steep terrains in the west (Yang et al. 2015), there are different characteristics in MCSs and associated rainfall extremes. Therefore, a comparison between these two areas is of great interest in order to improve the understanding about regional variations of extreme rainfall events.

To compare MCS-caused extreme rainfall events' characteristics between the United States and China, this section is based on the work of SJ06. In SJ06, 24-h precipitation data was used to select extreme rainfall cases. The event was considered as an extreme precipitation event when one or more gauges reported a 24-h rainfall total greater than the 50-yr recurrence interval amount. However, the hourly rainfall dataset and the percentile threshold method were used to determine precipitation events in this study. Since different data and thresholds may have an impact on the comparison, the results shown here only represent rough estimates and conclusions.

As in SJ06, MCS-related events were divided into TL/AS, BB, LS, PS, TS, multiple MCSs, and other MCSs. Therefore, the comparison hereafter is based on the first six types. The main findings are as follows. First, over $66.3 \%$ of all the extreme rainfall cases from 1999 to 2003 were classified as MCS type in the United States, and TL/AS type was the most common rainfall producer. However, a lower percentage of rainfall events fall into MCS type over East China, accounting for only $35.78 \%$ of the total samples between 2016 and 2017. It was also found that multiple-MCS type is the most common MCS-extreme-rainfall type over East China, accounting for $9.31 \%$ of the total extreme rainfall events. In addition to the data inhomogeneities discussed above, this difference is mainly attributed to the fact that mei-yu front is an important system for the occurrence of heavy rainfall in summer over East China and its vicinity (e.g., Chen 2004; Ding and Chan 2005; Ge et al. 2008; Xu et al. 2009; Kosaka et al. 2011). Within its development and propagation, it is often accompanied by the initiation and dissipation of MCSs. 

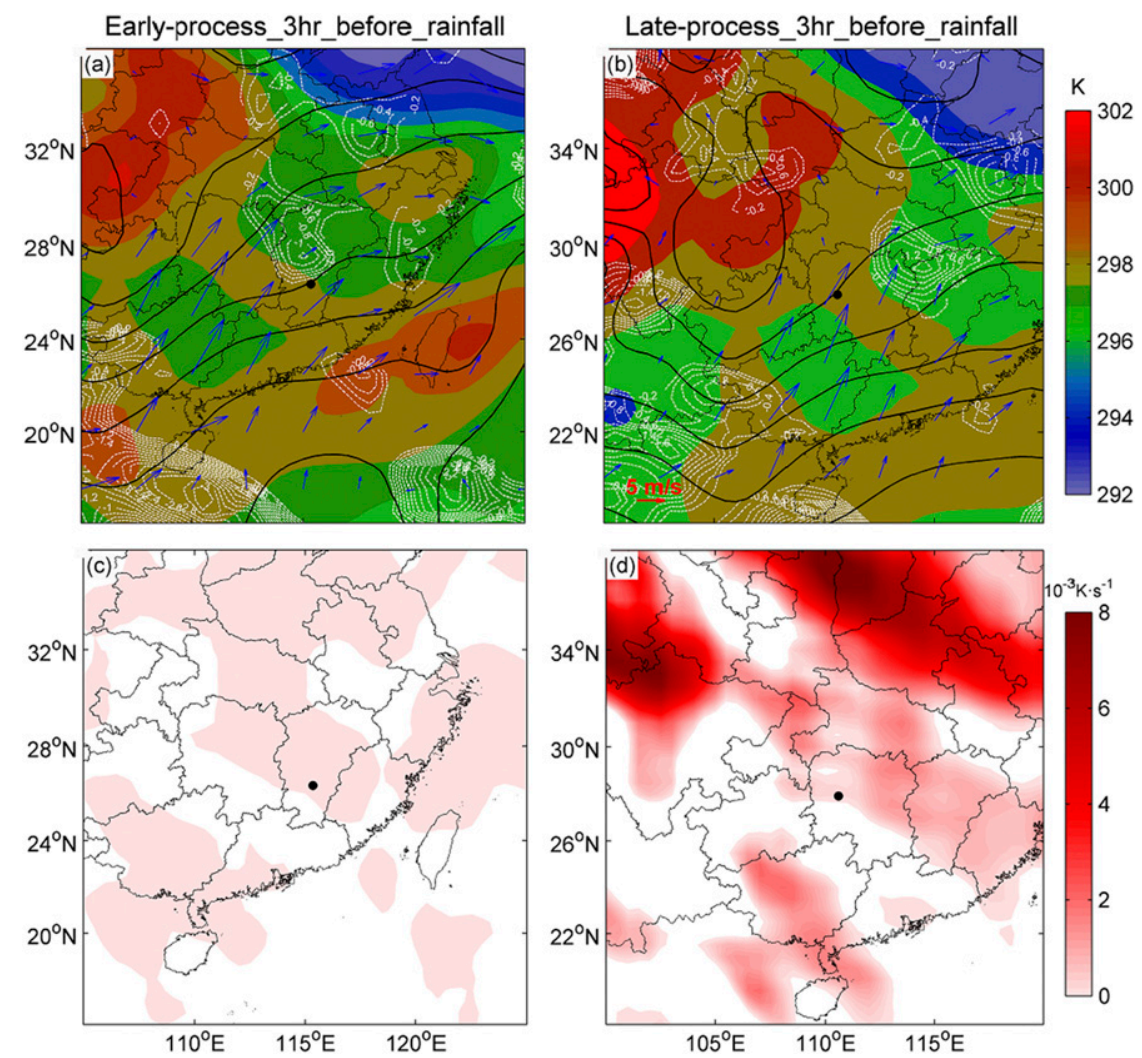

FIG. 21. (top) As in Fig. 16, but for the (a) early-maturing and (b) late-maturing processes in the event from 17 to $18 \mathrm{Jul} 2016$. (bottom) Warm-air advection $\left(10^{-3} \mathrm{~K} \mathrm{~s}^{-1}\right)$ for the two processes: (c) the early-maturing process and (d) the late-maturing process. The black point in all panels is the most extreme rainfall-occurrence point.

From the perspective of spatial distribution, there are both similarities and differences between the United States and China. For example, MCS-related events occur more frequently along the southern coastal areas in both countries. From south to north and from the coast to the inland, the occurrence of events gradually decreases. However, in the northern part of the two areas, the frequency of events is relatively evenly distributed in the United States whereas there are only sparse high-frequency extreme rainfall regions over northeast China.

Finally, the events in the two locations exhibit different temporal characteristics. The seasonal cycle is more pronounced in China. Specifically, in parts of the United States, there are some extreme events in the other seasons, but it seems that almost every case in China is in the warm season.

\section{Summary and discussion}

A total of 204 extreme rainfall cases over East China were identified by using hourly rain gauge observations in 2016-17. To quantify the differences of various weather systems in producing extreme precipitation, the composite Doppler radar mosaics and weather maps were used to classify the cases into five types: synoptic, tropical, MCSs, small-scale storms, and unclassified

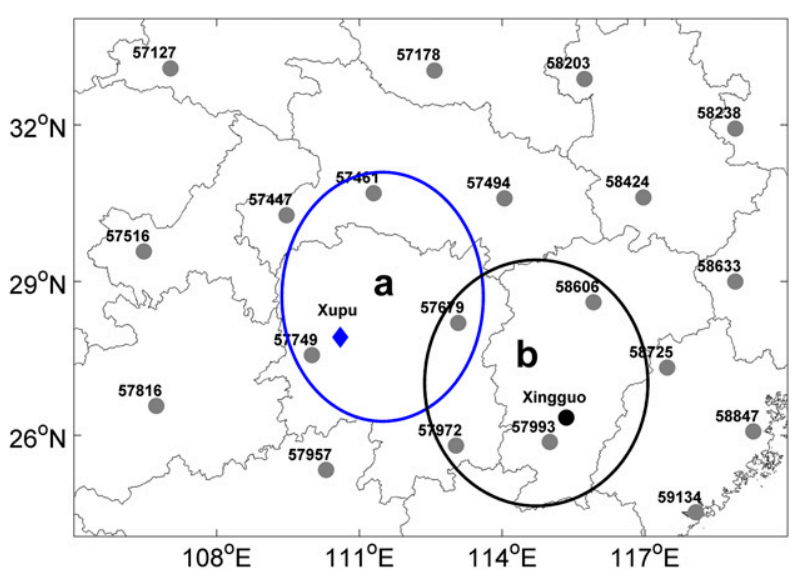

FIG. 22. The distribution of the rawinsondes in parts of East China (gray points), where in area a (the blue circle) are the stations used to estimate the mesoscale conditions of Xupu, and in area b (the black circle) are the stations for the calculation of Xingguo. The indications of the blue diamond and the black spot are the same as in Fig. 20. 
Skew-T / log-P Diagram
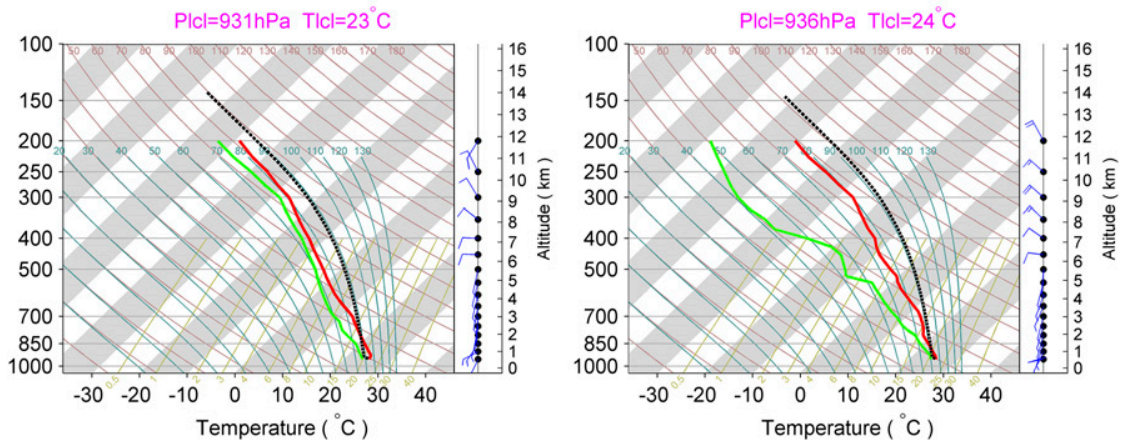

FIG. 23. As in Fig. 17, but for the soundings of Xingguo at (left) 1200 CST 17 Jul 2016 and (right) Xupu at $0000 \mathrm{CST} 17 \mathrm{Jul} 2016$. The sounding for each point was obtained by calculating the average value of the rawinsondes selected in Fig. 22. Note that the precipitation start times of the two stations are 1500 CST 17 Jul and 0300 CST 17 Jul, respectively. Since the actual observation is available every $6 \mathrm{~h}$, the average values at 1200 CST $17 \mathrm{Jul}$ and 0300 CST $17 \mathrm{Jul}$ were approximate the environments of the precipitation occurrences.

type. The synoptic events were then put into front and vortex/shear line type, while MCS-related events were arranged into TL/AS, BB, LS, PS, TS, disorganized, and multiple MCSs subclassification. Further analyses were performed to explore differences for subtypes of MCSs in the spatial-temporal and precipitation characteristics.

This study recognized 73 MCS-related extreme rainfall events with the maximum frequency of occurrence in South China along the coastline near southern Fujian Province. Three secondary frequency maxima were located in Hunan, Zhejiang, and Anhui, and Henan and Shandong Provinces, respectively. The extreme rainfall events ranged from April to October, and the peak month of occurrence was July. From spring to summer, the area of occurrence shifted from south to north, and went back to the south in autumn. The reason for this shift may be related to the propagation of the EASM and the movement of WPSH. Additionally, from the perspective of diurnal cycle, many events occurred from afternoon to early evening, matured around late afternoon and ended before dark.

Identification of the extreme rainfall events allowed for further analysis of precipitation characteristics. For all the selected MCS-caused cases, the longest sustaining cases were produced by multiple-MCS type. Two other long-lasting cases were results of TL and BB. By using CFSv2 reanalysis and rawinsondes, the initiation environment was further studied after dividing the multipleMCS events into early-maturing and late-maturing categories. The analysis shows that the two categories both have a southwest low-level jet, strong warm-air advection and convective instability before rainfall occurrence. However, lifting, moisture and instability were distinguishable between the early-maturing and latematuring cases. The composite of early-maturing cases had obvious upward lift, a moister environment and
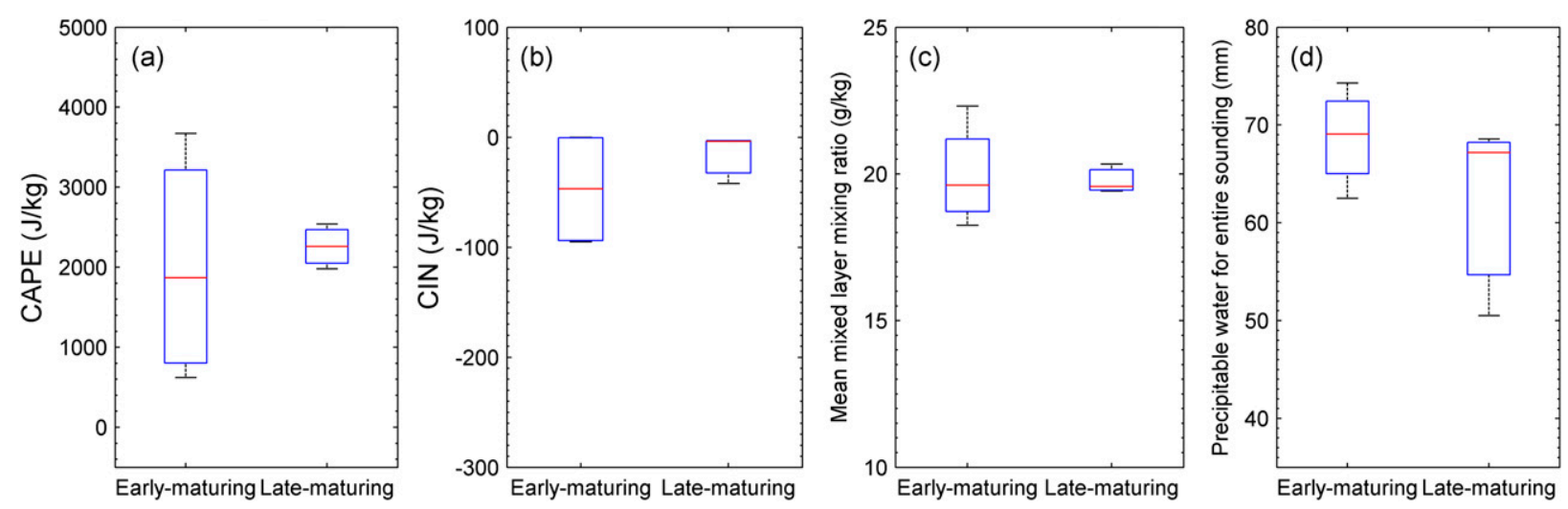

FIG. 24. As in Fig. 18, but each panel shows the properties of (left) the four stations in area a at 1200 CST 17 Jul 2016 and (right) the three stations in area b at 0000 CST $17 \mathrm{Jul} 2016$. 
smaller SBCAPE and SBCIN in the column above the most extreme rainfall-occurrence point compared to the late-maturing composite.

Finally, a rough comparison between MCS-caused extreme rainfall events over China and the United States has been conducted. It is found that the frequency of extreme precipitation events caused by MCSs is slightly higher in the United States than that over China. The events in both areas occur more in the southern region and gradually decrease to the north. The difference is that the occurrence in the northern United States is evenly distributed, while more concentrated to the northeast in North China. Further, the events in China exhibit more pronounced seasonal cycle.

The present study provides a basic description of the extreme precipitation events associated with MCSs over East China in 2016-17. In subsequent studies, additional years of data will be added as available to reinforce and extend the conclusions of the current work. Meanwhile, focus will be given to investigating the mechanism of precipitation generation and development by using more detailed observational analysis and numerical simulations of specific cases.

Acknowledgments. Precipitation data and radar mosaics were provided by Chinese National Meteorological Center. The authors would like to acknowledge Samuel J. Childs for the correction of vocabulary and grammar, and two anonymous reviewers for their suggestions that helped to improve the manuscript. This research is sponsored by the National Natural Science Foundation of China (41430427), the National Key Research and Development Program of China (2017YFC1502100), China Scholarship Council, and Postgraduate Research and Practice Innovation Program of Jiangsu Province (KYCX17_0876).

\section{REFERENCES}

Bao, M., 2007: The statistical analysis of the persistent heavy rain in the last 50 years over China and their backgrounds on the large-scale circulation (in Chinese). Chin. J. Atmos. Sci., 31, 779-792.

Buzzi, A., and L. Foschini, 2000: Mesoscale meteorological features associated with heavy precipitation in the southern Alpine region. Meteor. Atmos. Phys., 72, 131-146, https://doi.org/ 10.1007/s007030050011.

Chang, C.-P., S. C. Hou, H. C. Kuo, and G. T. J. Chen, 1998: The development of an intense East Asian summer monsoon disturbance with strong vertical coupling. Mon. Wea. Rev., 126, 2692-2712, https:// doi.org/10.1175/1520-0493(1998)126<2692:TDOAIE > 2.0.CO;2.

Chen, G. T.-J., 2004: Research on the phenomena of meiyu during the past quarter century: An overview. East Asian Monsoon, C.-P. Chang, Ed., World Scientific, 357-403, https://doi.org/ 10.1142/9789812701411_0010.

_ C.-C. Wang, and D. T.-W. Lin, 2005: Characteristics of lowlevel jets over northern Taiwan in mei-yu season and their relationship to heavy rain events. Mon. Wea. Rev., 133, 20-43, https://doi.org/10.1175/MWR-2813.1.

Chen, H., T. Zhou, R. Yu, and J. Li, 2009: Summer rain fall duration and its diurnal cycle over the US Great Plains. Int. J. Climatol., 29, 1515-1519, https://doi.org/10.1002/ joc. 1806 .

Chen, J., Y. Zheng, X. Zhang, and P. Zhu, 2013: Distribution and diurnal variation of warm-season short-duration heavy rainfall in relation to the MCSs in China. Acta Meteor. Sin., 27, 868-888, https://doi.org/10.1007/s13351-013-0605-x.

Chen, X., K. Zhao, M. Xue, B. Zhou, X. Huang, and W. Xu, 2015: Radar-observed diurnal cycle and propagation of convection over the Pearl River Delta during Mei-Yu season. J. Geophys. Res. Atmos., 120, 12 557-12 575, https://doi.org/10.1002/ 2015JD023872.

Chen, Y., X. Yu, Y. Yang, H. Wang, and H. Liu, 2016: Analysis of an occluded-shape mesoscale convective system (MCS) and concomitant mesoscale convective vortex (MCV) in Jiangsu (in Chinese). Meteor. Mon., 42, 166-173.

Davis, R. S., 2001: Flash flood forecast and detection methods. Severe Convective Storms, C.A. Doswell, Ed., Amer. Meteor. Soc., 481-525.

Ding, Y., and J. C. L. Chan, 2005: The East Asian summer monsoon: An overview. Meteor. Atmos. Phys., 89, 117-142, https:// doi.org/10.1007/s00703-005-0125-z.

French, A. J., and M. D. Parker, 2008: The initiation and evolution of multiple modes of convection within a meso-alpha-scale region. Wea. Forecasting, 23, 1221-1252, https:/doi.org/10.1175/ 2008WAF2222136.1.

Ge, Q., X. Guo, J. Zheng, and Z. Hao, 2008: Meiyu in the middle and lower reaches of the Yangtze River since 1736. Chin. Sci. Bull., 53, 107-114, https://doi.org/10.1007/s11434-007-0440-5.

Houze, R. A., Jr., 1977: Structure and dynamics of a tropical squallline system. Mon. Wea. Rev., 105, 1540-1567, https://doi.org/ 10.1175/1520-0493(1977)105<1540:SADOAT>2.0.CO;2.

_ B. F. Smull, and P. Dodge, 1990: Mesoscale organization of springtime rainstorms in Oklahoma. Mon. Wea. Rev., 118, 613-654, https://doi.org/10.1175/1520-0493(1990)118<0613: MOOSRI $>2.0 . \mathrm{CO} ; 2$.

Houze, R. A., D. C. Wilton, and B. F. Smull, 2007: Monsoon convection in the Himalayan region as seen by the TRMM Precipitation Radar. Quart. J. Roy. Meteor. Soc., 133, 13891411, https://doi.org/10.1002/qj.106.

Hu, B., and E. Pan, 1996: Two kinds of cyclonic disturbances and their accompanied heavy rain in the Yangtze River Valley during the Mei-Yu period (in Chinese). Quart. J. Appl. Meteor., 2, 138-144.

Huang, R., Y. Xu, P. Wang, and L. Zhou, 1998: The features of the catastrophic flood over the Changjiang River basin during the summer of 1998 and cause exploration (in Chinese). Climatic Environ. Res., 3, 300-313.

- Q. Zhang, and S. Ruan, 2005: Prediction and warning of meteorological disasters in China and scientific decision for the prevention and mitigation of these disasters (in Chinese). China Meteorological Press, 148 pp.

Huang, X., H. Liu, X. Yin, H. Zhou, and X. Shi, 2008: Analysis of the characteristics in a supercell storm event in China. 24th Conf. on Severe Local Storms, Savannah, GA, Amer. Meteor. Soc., P9.1, https://ams.confex.com/ams/24SLS/webprogram/ Paper141607.html.

— , Y. Li, J. Feng, J. Wang, Z. Wang, S. Wang, and Y. Zhang, 2015: Climate characteristics of precipitation and extreme drought events in Northwest China (in Chinese). Acta Ecol. Sin., 35, 1359-1370. 
Jiang, Z., D.-L. Zhang, R. Xia, and T. Qian, 2017: Diurnal variations of presummer rainfall over southern China. J. Climate, 30, 755-773, https://doi.org/10.1175/JCLI-D-15-0666.1.

Jirak, I. L., W. R. Cotton, and R. L. McAnelly, 2003: Satellite and radar survey of Mesoscale Convective System development. Mon. Wea. Rev., 131, 2428-2449, https://doi.org/10.1175/15200493(2003)131<2428:SARSOM >2.0.CO;2.

Johnson, R. H., 2004: Organization of Mesoscale Convective Systems. Sixth Int. GAME Conf., Kyoto, Japan, World Climate Research Programme.

- S. L. Aves, P. E. Ciesielski, and T. D. Keenan, 2005: Organization of oceanic convection during the onset of the 1998 East Asian summer monsoon. Mon. Wea. Rev., 133, 131-148, https://doi.org/10.1175/MWR-2843.1.

Kosaka, Y., S.-P. Xie, and H. Nakamura, 2011: Dynamics of interannual variability in summer precipitation over East Asia. J. Climate, 24, 5435-5453, https://doi.org/10.1175/ 2011JCLI4099.1.

Laing, A. G., and J. M. Fritsch, 2000: The large-scale environments of the global populations of mesoscale convective complexes. Mon. Wea. Rev., 128, 2756-2776, https://doi.org/10.1175/15200493(2000) $128<2756$ :TLSEOT $>2.0$.CO;2.

LeMone, M. A., E. J. Zipser, and S. B. Trier, 1998: The role of environmental shear and thermodynamic conditions in determining the structure and evolution of mesoscale convective systems during TOGA COARE. J. Atmos. Sci., 55 , 3493-3518, https://doi.org/10.1175/1520-0469(1998)055<3493: TROESA $>2.0 . \mathrm{CO} ; 2$.

Lin, Y.-L., S. Chiao, T.-A. Wang, M. L. Kaplan, and R. P. Weglarz, 2001: Some common ingredients for heavy orographic rainfall. Wea. Forecasting, 16, 633-660, https://doi.org/10.1175/15200434(2001)016<0633:SCIFHO > 2.0.CO;2.

Loehrer, S. M., and R. H. Johnson, 1995: Surface pressure and precipitation life cycle characteristics of pre-storm mesoscale convective systems. Mon. Wea. Rev., 123, 600-621, https:// doi.org/10.1175/1520-0493(1995)123<0600:SPAPLC >2.0.CO;2.

Luo, Y., Y. Gong, and D.-L. Zhang, 2014: Initiation and organizational modes of an extreme-rain-producing mesoscale convective system along a mei-yu front in east China. Mon. Wea. Rev., 142, 203-221, https://doi.org/10.1175/MWR-D-13-00111.1.

— , M. Wu, F. Ren, J. Li, and W.-K. Wong, 2016: Synoptic situations of extreme hourly precipitation over China. J. Climate, 29, 8703-8719, https://doi.org/10.1175/JCLI-D-16-0057.1.

Meng, Z., D. Yan, and Y. Zhang, 2013: General features of squall lines in east China. Mon. Wea. Rev., 141, 1629-1647, https:// doi.org/10.1175/MWR-D-12-00208.1.

Moncrieff, M. W., and J. S. A. Green, 1972: The propagation and transfer properties of steady convective overturning in shear. Quart. J. Roy. Meteor. Soc., 98, 336-352, https://doi.org/10.1002/ qj. 49709841607.

Moore, J. T., F. H. Glass, C. E. Graves, S. M. Rochette, and M. J. Singer, 2003: The environment of warm-season elevated thunderstorms associated with heavy rainfall over the central United States. Wea. Forecasting, 18, 861-878, https://doi.org/ 10.1175/1520-0434(2003)018<0861:TEOWET >2.0.CO;2.

Nicolini, M., K. M. Waldron, and J. Paegle, 1993: Diurnal oscillations of low-level jets, vertical motion, and precipitation: A model case study. Mon. Wea. Rev., 121, 2588-2610, https://doi.org/ 10.1175/1520-0493(1993)121<2588:DOOLLJ > 2.0.CO;2.

Parker, M. D., 2007: Simulated convective lines with parallel stratiform precipitation. Part I: An archetype for convection in along-line shear. J. Atmos. Sci., 64, 267-288, https://doi.org/ 10.1175/JAS3853.1.
, and R. H. Johnson, 2000: Organizational modes of midlatitude mesoscale convective systems. Mon. Wea. Rev., 128, 3413-3436, https://doi.org/10.1175/1520-0493(2001)129<3413: OMOMMC $>2.0 . \mathrm{CO} ; 2$.

Pettet, C. R., and R. H. Johnson, 2003: Airflow and precipitation structure of two leading stratiform mesoscale convective systems determined from operational datasets. Wea. Forecasting, 18, 685-699, https://doi.org/10.1175/1520-0434(2003)018<0685: AAPSOT $>2.0 . \mathrm{CO} ; 2$.

Pope, M., C. Jakob, and M. J. Reeder, 2008: Convective systems of the North Australian monsoon. J. Climate, 21, 5091-5112, https://doi.org/10.1175/2008JCLI2304.1.

Rigo, T., and M. C. Llasat, 2004: A methodology for the classification of convective structures using meteorological radar: Application to heavy rainfall events on the Mediterranean coast of the Iberian Peninsula. Nat. Hazards Earth Syst. Sci., 4, 59-68, https://doi.org/10.5194/nhess-4-59-2004.

_, and M.-C. Llasat, 2007: Analysis of mesoscale convective systems in Catalonia using meteorological radar for the period 1996-2000. Atmos. Res., 83, 458-472, https://doi.org/10.1016/ j.atmosres.2005.10.016.

Rotunno, R., J. B. Klemp, and M. L. Weisman, 1988: A theory for strong, long-lived squall lines. J. Atmos. Sci., 45, 463-485, https://doi.org/10.1175/1520-0469(1988)045<0463:ATFSLL> 2.0.CO;2.

Schiesser, H. H., R. A. Houze, and H. Huntrieser, 1995: The mesoscale structure of severe precipitation systems in Switzerland. Mon. Wea. Rev., 123, 2070-2097, https://doi.org/10.1175/ 1520-0493(1995)123<2070:TMSOSP > 2.0.CO;2.

Schumacher, R. S., and R. H. Johnson, 2006: Characteristics of U.S. extreme rain events during 1999-2003. Wea. Forecasting, 21, 69-85, https://doi.org/10.1175/WAF900.1.

$\longrightarrow$, and — 2009: Quasi-stationary, extreme-rain-producing convective systems associated with midlevel cyclonic circulations. Wea. Forecasting, 24, 555-574, https://doi.org/10.1175/ 2008WAF2222173.1.

Smith, A. M., G. M. McFarquhar, R. M. Rauber, J. A. Grim, M. S. Timlin, B. F. Jewett, and D. P. Jorgensen, 2009: Microphysical and thermodynamic structure and evolution of the trailing stratiform regions of mesoscale convective systems during BAMEX. Part I: Observations. Mon. Wea. Rev., 137, 1165-1185, https:// doi.org/10.1175/2008MWR2504.1.

Stevenson, S. N., and R. S. Schumacher, 2014: A 10-year survey of extreme rainfall events in the central and eastern United States using gridded multisensor precipitation analyses. Mon. Wea. Rev., 142, 3147-3162, https://doi.org/10.1175/MWR-D-13-00345.1.

Sun, J., X. Zhang, L. Zheng, G. Zhang, S. Zhao, and S. Tao, 2004: A study of vortex and its Mesoscale Convective System during China heavy rainfall experiment and study in 2002. Chin. J. Atmos. Sci., 28, 675-691.

Tao, S.-Y., and Y.-H. Ding, 1981: Observational evidence of the influence of the Qinghai-Xizang (Tibet) Plateau on the occurrence of heavy rain and severe convective storms in China. Bull. Amer. Meteor. Soc., 62, 23-30, https://doi.org/10.1175/ 1520-0477(1981)062<0023:OEOTIO >2.0.CO;2.

—, Q. Zhang, and S. Zhang, 1998: The great floods in the Changijang River valley in 1998 (in Chinese). Climatic Environ. Res., 4, 290-299.

Tu, K., Z. Yan, and W. Dong, 2010: Climatic jumps in precipitation and extremes in drying North China during 1954-2006. J. Meteor. Soc. Japan, 88, 29-42, https://doi.org/10.2151/jmsj.2010-103.

Vila, D. A., L. A. T. Machado, H. Laurent, and I. Velasco, 2008: Forecast and tracking the evolution of cloud clusters 
(ForTraCC) using satellite infrared imagery: Methodology and validation. Wea. Forecasting, 23, 233-245, https://doi.org/ 10.1175/2007WAF2006121.1.

Wang, X., and C. Cui, 2012: Analysis of the linear mesoscale convective systems during Mei-Yu period in the middle and lower reaches of the Yangtze River. Part I: Organization mode features (in Chinese). Acta Meteor. Sin., 70, 909-923.

— B. Hu, H. Li, and C. Cui, 2011: Stream structure of a convective line with leading stratiform precipitation during meiyu period (in Chinese). Plateau Meteor., 30, 1052-1066.

Xu, W., and E. J. Zipser, 2011: Diurnal variations of precipitation, deep convection, and lightning over and east of the eastern Tibetan Plateau. J. Climate, 24, 448-465, https://doi.org/ 10.1175/2010JCLI3719.1.

- - , and C. Liu, 2009: Rainfall characteristics and convective properties of mei-yu precipitation systems over South China, Taiwan, and the South China Sea. Part I: TRMM observations. Mon. Wea. Rev., 137, 4261-4275, https://doi.org/ 10.1175/2009MWR2982.1.

Yan, Z., and C. Yang, 2000: Geographic patterns of extreme climate changes in China during 1951-1997 (in Chinese). Climatic Environ. Res., 5, 267-272.

Yang, X., J. Fei, X. Huang, X. Cheng, L. M. V. Carvalho, and H. He, 2015: Characteristics of mesoscale convective systems over China and its vicinity using geostationary satellite FY2. J. Climate, 28, 4890-4907, https://doi.org/10.1175/JCLI-D-1400491.1.

Yao, X., G. Wu, Y. Liu, and H. Liu, 2007: Case study on the impact of the vortex in the easterlies over the tropical upper troposphere on the subtropical anticyclone over the western Pacific Ocean (in Chinese). Acta Meteor. Sin., 65, 198-207.

Ye, D., and R. Huang, 1996: Research on the regularity and cause of drought and flooding in the Yangtze River Valley and the Yellow River Valley (in Chinese). Shandong Science and Technology, 387 pp.

Yi, X., Z. Li, X. Yao, H. Wang, and X. Sun, 2011: An analysis of the multi-scale structure and evolution of a meso-scale occluding convective system (in Chinese). Acta Meteor. Sin., 69, 249-262.
Yu, H., S. Liu, N. Zhao, D. Li, and Y. Yu, 2011: Characteristics of air temperature and precipitation in different regions of China from 1951 to 2009 (in Chinese). J. Meteor. Environ., 27, 1-11.

Yu, R., T. Zhou, A. Xiong, Y. Zhu, and J. Li, 2007: Diurnal variations of summer precipitation over contiguous China. Geophys. Res. Lett., 34, L01704, https://doi.org/10.1029/2006GL028129.

Yue, Z., S. Niu, and G. Liang, 2008: Structure models and disaster analyses of mesoscale convective system in Weibei Area of Shaanxi Province (in Chinese). J. Nanjing Inst. Meteor, 31, 395-402.

Zhai, P., and X. Zou, 2005: Changes in temperature and precipitation and their impacts on drought in China during 19512003 (in Chinese). Adv. Climate Change Res., 1, 16-18.

_ X. Xhang, H. Wan, and X. Pan, 2005: Trends in total precipitation and frequency of daily precipitation extremes over China. J. Climate, 18, 1096-1108, https://doi.org/10.1175/JCLI3318.1.

Zhang, Q., Y. Zhao, and S. Fan, 2016: Development of hourly precipitation datasets for national meteorological stations in China (in Chinese). Torrential Rain Disasters, 35, 182-186.

Zhao, S., and J. Sun, 2007: Study on cut-off low-pressure systems with floods over Northeast Asia. Meteor. Atmos. Phys., 96, 159-180, https://doi.org/10.1007/s00703-006-0226-3.

Zheng, L., J. Sun, X. Zhang, and C. Liu, 2013: Organizational modes of mesoscale convective systems over central east China. Wea. Forecasting, 28, 1081-1098, https://doi.org/10.1175/ WAF-D-12-00088.1.

Zheng, Y., J. Chen, and P. Zhu, 2008: The characteristic of distribution and spatiotemporal variations of deep convection over China and its vicinity during summer (in Chinese). Chin. Sci. Bull., 53, 471-481,

—, M. Xue, B. Li, J. Chen, and Z. Tao, 2016: Spatial characteristics of extreme rainfall over China with hourly through 24-hour accumulation periods based on national-level hourly rain gauge data. Adv. Atmos. Sci., 33, 1218-1232, https:// doi.org/10.1007/s00376-016-6128-5.

Zhou, T., R. Yu, H. Chen, A. Dai, and Y. Pan, 2008: Summer precipitation frequency, intensity, and diurnal cycle over China: A comparison of satellite data with rain gauge observations. J. Climate, 21, 3997-4010, https://doi.org/10.1175/2008JCLI2028.1. 